\title{
EL CONOCIMIENTO DEL VALOR: TEORÍA DE LOS VALORES A MEDIADOS DEL SIGLO XX
}

Este estudio es un resumen sobre el estado presente de la discusión en torno al conocimiento de los valores. Si los valores pueden ser conocidos o no pueden serlo, es el tema fundamental de la axiología; es un problema que surgió con Kant y su dicotomía entre el mundo fenoménico y el mundo nouménico, al segundo de los cuales se atribuye valor. Puesto que la razón teórica se podía aplicar legítimamente sólo al reino fenoménico, resultaba que el reino del valor quedaba privado de estructura lógica; y, así, lo que había constituido antes una cuestión demasiado seria -el conocimiento del bien- se convirtió entonces en un problema profundo y casi desesperado en la nueva terminología de la teoría de los valores. Kant usa continuamente la palabra "valor" sin ni siquiera definirla; y en la base de su teoría radica el principio de su indefinibilidad; pues el valor se funda en la idea de la libertad, la cual es parte del reino nouménico y, por lo tanto, la teoría no puede tener acceso a ella. Antes de Kant había habido pocas dudas respecto de si el bien puede ser conocido; es más, menos duda que la que pudiera haber respecto de la cognoscibilidad de los hechos. Todavía en 1695 Locke $^{1}$ dudaba de que pudiera haber una ciencia de la naturaleza -a pesar de la obra del "incomparable señor Newton"-, pero nunca dudó de que pudiera haber una ciencia de la moral, tan cierta como la matemática. Con eso no hacía sino expresar un criterio que desde Platón estaba firmemente anclado en la filosofía.

Sin embargo, Kant tuvo buen fundamento para su dicotomía. El conocimiento del valor es básicamente diferente del conocimiento de los hechos, por la simple razón de que los valores son fundamentalmente diferentes de los hechos. Con todo, no hay duda entre los hombres -excepto los adictos radicales al positivismo lógico-, de que valoramos y de que los juicios de valor, como por ejemplo, "engañar es malo", tienen alguna significación, significan algo. Entonces la cuestión consiste en preguntarnos: ¿qué significan tales juicios de valor? $Y$, en un plano todavía más fundamental: ¿qué significa que ellos signifiquen? ¿Qué clase de significación tienen? ¿Refiérense a algo así como un reino de valores, o no se refieren a nada? $Y$ en el caso de la última hipótesis, ¿cuál sería la significación que posiblemente les cupiese? ¿Serían meramente ruidos hechos por la gente para expresar sus actitudes de agrado y de desagrado, y, por ende, sujetos más bien a la psicología que a la

1 Véase la Bibliografía al fin del artículo. 
filosofía, al modo de los símbolos de los ensueños o de las expresiones psicosomáticas, como el hipo o las eyaculaciones? ¿Son funciones relativas a la situación y pertenecen, por lo tanto, a la sociología y a la antropología, al igual que las fórmulas mágicas y las manifestaciones ceremoniales? ¿O son, en cambio, una especie de expresiones o proposiciones no referenciales, como le sucede a las proposiciones de la matemática o de la logica, las cuales, aunque no se refieren a nada, son, sin embargo, aplicables a todo - tal cual y como lo suponían Platón y Locke, pero no Kant? Todas estas tesis han tenido y tienen representantes: la primera - la tesis ontológica de un reino de valores- es la predominante en la Europa Continental, en Hispanoamérica y en Asia; la segunda -la opinión de que los juicios de valor son manifestaciones psicológicas o situacionales- es la que prepondera en Inglaterra y en los Estados Unidos; y la tercera posición - de una validez formal y universal de juicios de valor- es sostenida por algunos pensadores en Europa y en las Américas.

Desde luego, la razón de esa variedad azorante de opiniones sobre el valor consiste en que nadie sabe efectivamente lo que los valores sean. Si los valores fuesen una parte del mundo sensible, la ciencia natural daría cuenta de ellos $-\mathrm{y}$ algunos filósofos resuelven este problema diciendo simplemente que los valores pertenecen a los hechos de experiencia y que la ciencia natural puede explicarlos. Pero otros autores sostienen con igual convicción que los valores no son hechos de experiencia externa, y que, por consiguiente, las ciencias de la naturaleza no se aplican a ellos. Esto no significa en modo alguno que no haya ninguna ciencia que se dedique al conocimiento de los valores. Tampoco los números pertenecen al mundo sensible, $y$, sin embargo, nadie se atrevería a sostener que cuando decimos " $\mathrm{a}$ " $=1$ " con ello expresamos meramente una emoción o una fórmula mágica, pues lo que con ello expresamos es una fórmula matemática. La dificultad con la axiología consiste en que no poseemos un sistema dentro del cual los juicios de valor encuentren propiamente su respectivo lugar, como, por ejemplo, sucede con los juicios matemáticos dentro de la matemática. Donde no hay un sistema hay confusión; y por esta razón los juicios de valor están expuestos a una franca lucha libre abierta a todos, en la cual algunos anuncian que tales juicios se refieren a algo, otros, que no se refieren a nada, y otros, a su vez, dicen que expresan sblo observaciones psicológicas o sociológicas. Así acontece que los valores tienen la posición epistemológica de cosas desconocidas - como la de los platos voladores. Algunos creen que hay valores; otros que no los hay; y algunos que son meramente alucinaciones. $O$, si nos retrotraemos a ejemplos históricos, podemos decir que los valores tienen hoy en día la misma condición epistemológica que la piedra filosofal, la fuente de juventud, o el flogisto, el principio del fuego. Algunos han dicho que estas cosas existen, y otros que no; y C. G. Jung ha mostrado que realmente son símbolos de la mente inconsciente. El camino para romper el círculo mágico, del cual eran parte estas 
representaciones y otras imágenes precientíficas, fue romper completamente con el cuadro íntegro del mundo que ellas representaban, y hacer un nuevo inicio original. Esta fue la realización llevada a cabo en otra época por $\mathrm{Ga}$ lileo, el cual inventó un marco de referencia enteramente nuevo, el matemático, dentro del cual se pensara en el cielo y en la tierra. Su sencilla fórmula abrió - por medio de argumentos racionales y no de persuasión mágicael almacén de la naturaleza, del cual hemos sacado la energía de los tiempos modernos y actuales.

Así, pues, nuestra presente confusión sobre el valor no es nueva ni única - es simplemente una especie de conciencia de lo desconocido-; es debida tan sólo a la presencia de un grave problema. Para acometer un problema, por ejemplo, para hallar $\mathrm{X}$, hay tres posibilidades logicas y solamente esas tres: "I) Decir que no hay tal X, lo cual termina el problema en el acto; 2) decir que hay $\mathrm{X}$, y entonces empezar a buscarlo y a buscar caminos para hallarlo, o 3) la posición intermedia de decir que hay y no hay X: lo hay en un sentido y no lo hay en otro". La primera posición consiste en decir: "No, no hay ningún valor"; la segunda en manifestar: "Sí, hay valor"; la tercera, en declarar: "Sí, hay valor, pero..." o "No, no hay valor, pero...". La primera es la posición incognoscitivista; la segunda, es la cognoscitivista; y la tercera, la semi-cognoscitivista o semi-incognoscitivista. Esas tres posiciones tienen hoy en día notables representantes, cuyas opiniones van desde la no existencia e incognoscibilidad de los valores, hasta su existencia y cognoscibilidad exacta.

Si tomamos la comprensión lógica del valor como meta final hacia la cual la axiología debiera aspirar, obtenemos un cuadro o una gama que comprende desde aquellos que niegan toda posibilidad de conocimiento estimativo, hasta aquellos otros que no sólo afirman tal posibilidad, sino que además establecen sistemas axiológicos. Los últimos enfocan el problema sobre la base de cinco proposiciones, cada una de las cuales es negada por una $u$ otra escuela axiológica, a saber: 1) Hay valor; 2) el valor es cognoscible; 3) el conocimiento axiológico consiste en la sistematización; 4) la sistematización se basa en formulaciones axiomáticas y en una extensión deductiva de la esencia de la experiencia axiológica; 5) el sistema axiológico se demuestra por el alcance de su aplicabilidad al mundo de los valores. Hay algunos cognoscitivistas que recorren enteramente todo este camino; pero hay otros que están de acuerdo sólo con los puntos 1) y 2), esto es, con que hay valores, y con que pueden ser conocidos. Hay algunos incognoscitivistas que niegan el punto 1) o el punto 2) por completo. Pero hay muchos que niegan parcialmente el punto 2), sosteniendo que el fenómeno de valor, o bien no puede ser comunicado, o bien, de sus dos elementos constitutivos -el descriptivo y el normativo-, sólo es posible conocer el primero. Hay una numerosa escuela que niega el punto 3) insistiendo en que, el conocimiento de los valores no puede ser sistematizado, y tiene que ser descubierto en cada situación particular. Hay 
cognoscitivistas que aceptan los puntos 1), 2) y 3), pero niegan el 4), sosteniendo que el sistema tiene que ser más bien inductivo que deductivo. Sólo los cognoscitivistas que recorren todo el camino, construyen un sistema deductivo de axiología y lo aplican al mundo estimativo de un modo similar a como los naturalistas aplican el sistema de las matemáticas al mundo de la naturaleza.

Si llamamos incognoscitivistas a los que niegan el punto 1) o el 2), o ambos, y llamamos cognoscitivistas a los que afirman los puntos 1), 2) y 3), entonces aquellos que niegan parcialmente el punto 2) o aquellos que niegan el punto 3) serán semi-cognoscitivistas (o lo que es lo mismo, semi-incognoscitivistas).

Esta es la clasificación fundamental y epistemológica de los filósofos del valor. Pero hay otras subclasificaciones materiales. Algunos son empiristas, pues encuentran la esencia del valor en la experiencia, ora natural, ora no natural; otros son formalistas, en tanto que hallan la esencia del valor en la estructura de los juicios estimativos. Desde otros puntos de vista y de modo secante con las clasificaciones indicadas, se puede mencionar otra clasificación: naturalistas -que creen que el valor es un hecho natural o social-, ontologistas -que sostienen que es algo ontológico-, y fenomenólogos, los cuales entienden que el valor es un fenómeno sui generis, peculiarmente axiológico.

Así, pues, en conjunto podemos clasificar las teorías sobre los valores como sigue:

I. Incognoscitivistas. Entre ellos figuran:

1. Empiristas, quienes sostienen que únicamente lo empírico es cognoscible; niegan que el valor tenga naturaleza empírica o ninguna otra clase de naturaleza; $y$, por lo tanto, niegan su cognoscibilidad.

2. Formalistas, que sostienen que la experiencia axiológica aparece esencialmente en los juicios de valor, pero niegan que la lógica de estos juicios sea capaz de dar una explicación adecuada de tal experiencia.

II. Semi-Cognoscitivistas o semi-InCognoscittuistas. Entre éstos se cuentan los siguientes:

1. Empiristas (Emotivistas), que creen que el aspecto descriptivo (fáctico) de los juicios de valor es lógicamente analizable, pero que, en cambio, el aspecto emocional no descriptivo no es logicamente analizable, o no lo es de la misma manera que aquél.

2. Formalistas, que creen que las situaciones de valor aparecen con sentido en los juicios estimativos, y que hay una lógica de tales juicios, si bien esta lógica sea sui generis y dependa del contexto de cada situación.

III. Cognoscitrvistas. Entre los cuales figuran:

1. Naturalistas, que creen que el valor es un fenómeno observable y ana- 
lizable al igual que cualquier otro fenómeno natural o social. A su vez se subclasifican en:

A) Empiristas, que intentan hallar el valor en el contenido de las ciencias empíricas -naturales o sociales.

B) Formalistas, que se proponen encontrar el valor no tanto en el contenido de esas ciencias, sino más bien en el método de ellas.

2. No-naturalistas, para quienes el valor es un fenómeno sui generis. A su vez se subclasifican en:

A) Empiristas, que encuentran el valor en:

a) una experiencia ontológica, como un aspecto del Ser;

b) en una experiencia fenomenológica, en un reino sui generis.

B) Formalistas, que creen que hay una lógica aplicable a los fenómenos de valor, análoga a la que es aplicable a los fenómenos naturales.

Esta clasificación, que constituye una especie de espectroscopia, que va desde el incognoscitivismo al cognoscitivismo, pone orden no solamente en el campo teórico de la axiología, sino que además proporciona también una cierta visión evolutiva de su contenido, es decir, del modo de concebir el valor. Pues si, como sostuvieron algunos de los más radicales positivistas - quienes desde el punto de vista de la axiología son negativistas- el valor no es nada más que un ruido psicológico, entonces la valoración más concienzuda tendría lugar en la charla excitada de la selva primitiva. Tal modo de concebir la valoración presenta ésta en un nivel inferior desde el punto de vista racional al que obtiene cuando es concebida a manera de una forma de experiencia bien ordenada, sistemáticamente accesible y ricamente diferenciada, comparable en riqueza y comprensibilidad a la experiencia de hechos - tal y como lo sostienen los cognoscitivistas. Así, pues, mientras que las teorías axiológicas pueden ser ordenadas en una escala de racionalidad creciente, desde la incognoscibilidad del valor hasta definiciones tajantes y una sistematización, así también la experiencia axiológica refleja esta escala en una gradación evolutiva desde el ruido animal a la razón humana.

\section{INCOGNOSCTTIVISTAS}

1) Empiristas. El nadir de la filosofía de los valores se alcanz6 en 1936 en la obra de Ayer, ${ }^{2}$ quien sostiene que los juicios de. valor son un "sin-sentido literal" - no son proposiciones, ni empíricas ni analíticas, y no hacen referencia a nada; son meras "exclamaciones", ruidos psicosomáticos. La tarea del teórico de la ética, según Ayer, consiste en exponer la naturaleza puramente emotiva y pseudo-proposicional de los juicios normativos. Siguiendo a Ayer, algunos positivistas han cumplido la misión que aquél les asignó, y por varios caminos han analizado tales expresiones, v.gr., "mentir es malo", como imperativos ("no mientas"), como manifestaciones de un deseo ("deseo que 
no mientas"), como exclamaciones (“imentir!"), como intentos de persuadir ("repruebo la mentira; tú debieras también reprobarla"), como pronunciamientos ("mentir es malo" como función en una situación), etc. Todo el desenvolvimiento del positivismo desde 1936 se ha efectuado en la dirección de hacer los juicios de valor más y más comprensibles, sin considerarlos, no obstante, como racionales. Así, pues, el desarrollo va desde el in-cognoscitivismo al semi-cognoscitivismo. La distinción entre la parte descriptiva y la no descriptiva de un juicio de valor (v.gr., "tú no estás diciendo la verdad, „Bah!”) se ha mantenido estrictamente; y la relación entre las dos partes ("tú no estás diciendo la verdad" $y$ “ßBah!") se ha investigado como el problema central de la teoría de los valores - como lo había sido aunque de diferentes maneras desde Kant. Así, pues, en los últimos diez años no ha habido ninguna contribución estrictamente incognoscitivista. Se han producido ciertamente algunos análisis menores, aunque importantes, de la teoría incognoscitivista, en los que se ha pesado sus pros y sus contras, como por ejemplo, la obra de Harrison, ${ }^{3}$ quien, continuando una discusión iniciada por Barnes ${ }^{4}$ y Campbell, ${ }^{5}$ concluye que, a pesar de sus inadecuaciones esenciales, esta teoría, especialmente en su variante emotiva, explica algunos aspectos fundamentales de la vida ética, y muestra que en conjunto la ética puede habérselas sin proposiciones.

2) Formalistas. Sin embargo, ha habido una importante obra de in-cognoscitivismo formalista escrita por Hall, ${ }^{6}$ quien afirma taxativamente la proposición 1), es decir, afirma que hay valores, pero niega, aunque con atenuaciones, la proposición 2), que los valores puedan ser conocidos. El valor no es un fenómeno cognoscible; pero su estructura brilla a través de la estructura de los juicios que se hacen sobre él. Si entendemos esto último, podremos lograr una vislumbre de la esencia misma del valor. Con este método indirecto de conseguir indicios del reino del valor, Hall se sitúa próximo a los semicognoscitivistas: su acentuación de los imperativos le pone cerca de los empiristas semi-cognoscitivistas - los emotivistas-, mientras que su método analítico lo aproxima a los formalistas semi-cognoscitivistas y a su renuncia al conocimiento sistemático, al modo de Wittgenstein.

\section{SEMI-COGNOSctivivistas}

1) Empiristas (Emotivistas). La diferencia entre los empiristas semi-cognoscitivistas y los formalistas consiste en que los primeros, los empiristas, tratan la relación y valoración subrayando una distinción entre propiedades no axiologicas y propiedades axiológicas, mientras que los segundos, los formalistas, tratan esa relación acentuando una distinción entre predicados no axiológicos y predicados axiologicos. Así Hallden y Edwards tratan aspectos de situaciones, más bien que aspectos de proposiciones. Hallden ${ }^{7}$ arranca de Hagerstrom, ${ }^{8}$. suponiendo, de modo contrario a como lo hace Hagerstrom, que los sentidos 
de las frases ordinarias valorativas son de estructura proposicional. Investigando esta estructura, Hallden encuentra "propiedades emotivas", derivadas por abstracción de contenidos emocionales que están localizados en objetos de la percepción. Hay conceptos de valor de un carácter originario, que no son conceptos psicológicos. Propiedades de valor como bueno, malo, justo, verdadero, bello, etc., no son en sí mismas propiedades emotivas. La proposición $x$ es. bueno se refiere en cierto modo a atributos no valorativos de $\mathrm{x}$, e implica que alguna propiedad emocional positiva se aplica $a x$. También Edwards ${ }^{\theta}$ observa la relación entre las propiedades no valorativas (o descriptivas) y las propiedades valorativas de una cosa. Las propiedades no valorativas o descriptivas son los términos de referencia de las propiedades valorativas; es decir, las palabras expresivas de valores son lo que él llama "expresiones poliguas", términos que tienen un gran número de puntos de referencia, entendiendo por "puntos de referencia" entidades expresivas más bien del contenido que de la extensión, a saber, colecciones o series de propiedades "determinantes de valores", que pueden ser diferentes en cada uso o acepción de la palabra de valor -observación que nos recuerda lo que dice Aristóteles sobre la homonimia de la palabra "bueno". 10 Sin embargo, a diferencia de Aristóteles, Edwards desarrolla este tema, en el plano de la lógica hasta un cierto punto, y más allá de este punto, en el plano de lo emotivo. Las cualidades de valor no son cualidades como la rojez o la dureza. No son cualidades simples, sino complejas. Sin embargo, Edwards no se dedica tanto a desarrollar esta complejidad lógicamente y a definir sistemáticamente en detalle la naturaleza de esta "poliguiidad", sino que más bien se contenta con enunciar la relación y sacar conclusiones generales de su existencia, considerando que lo más importante es darse cuenta de que la gente, cuando habla en términos de valor sobre el mismo tema, expresa desacuerdos en cuanto a la actitud. Así, Edwards basa el aspecto emotivo de los juicios de valor en el sentido "poliguo" de los términos de valor.

2) Formalistas. La escuela formalista semi-cognoscitivista, o lo que es lo mismo, semi-incognoscitivista, centrada geográficamente en Inglaterra, de modo especial en Oxford, con ramas en el Occidente Medio de los Estados Unidos, puede ser llamada la expansión axio-linguística de las enseñanzas de Wittgenstein -así como el libro de Hall, ${ }^{6}$ puede ser llamado la expansión axio-ontológica de éstas. Para Wittgenstein ${ }^{11}$ todas las categorías filosóficas descansan en abusos del lenguaje. Si Kant destruyó la razón especulativa para hacer lugar a la fe, Wittgenstein destruye lo que Kant había dejado para hacer lugar al lenguaje ordinario -con lo cual libera en absoluto la filosofía de la especulación y de la conceptualización. El único método de la filosofía es la descripción; pues la explicación, y todavía mucho más la definición, se interfieren con el uso real del lenguaje. El lenguaje no es nada más que un juego: jugado en pequeños contextos situacionales, con reglas que no es 
posible establecer sistemáticamente de una vez y para siempre, sino que se hacen sobre la marcha, y que cambian al proseguirla. La conceptualización destruye esta "textura abierta" del campo, y se interfiere con nuestra "clara" y "exacta" inteligencia de su variedad. Los fenómenos de valor no poseen propiedades comunes en el sentido de una clasificación, sino que pertenecen a grupos que presentan "parecidos de familia". El filósofo no debe pensar sobre el valor, sino que debe ser parte de la textura misma, "mirar y ver", y seguir el juego. Wittgenstein había dicho antes ${ }^{12}$ que la filosofía es una açtividad y no una doctrina. Todo lo que el filósofo debe hacer $-\mathrm{y}$ ésta es su misión- es "representar en un vistazo de conjunto" ("ïbersichtlich darstellen") cómo la palabra o frase que le preocupa es usada en los varios juegos del lenguaje en los que aparece.

Puesto que el lenguaje es un rasgo o componente de la situación, y puesto que el carácter situacional es su nota axiológica esencial, el lenguaje.de "pronunciamientos", esto es, el lenguaje como rasgo constitutivo de una situación, es especialmente relevante para la valoración. Sobre la base de la obra clásica de Austin, ${ }^{13}$ este aspecto de la doctrina axiologica de la escuela de Oxford ha sido desarrollado por Hart, Margaret MacDonald, R. C. Cross, L. J. Russell y otros. Hart ${ }^{14}$ establece una analogía entre las frases ordinarias y el discurso jurídico. La señorita MacDonald ${ }^{15}$ hace hincapié en que los juicios éticos deberían ser entendidos por analogía con ciertas clases de manifestaciones ceremoniales. Cross ${ }^{16}$ basa su estudio en la distinción establecida por Ryle entre "conocer cómo" y "conocer qué... tal y tal". L. J. Russell ${ }^{17}$ arguye que los juicios morales deben ser interpretados como propuestas. "Se puede argüir sobre propuestas: cabe dar razones en pro y en contra de ellas; pero estas razones son razones para hacer algo, y no razones para aceptar algo como verdadero."

Todas estas presentaciones son ejercicios en una nueva "lógica". Esta escuela sostiene que el razonamiento ético sigue una lógica sui generis, diferente tanto de la lógica inductiva como de la deductiva. Por así decirlo, tenemos que enfocar el microscopio a cada situación y examinar cómo son usados los términos de valor en cada situación. Al hacerlo así, como lo indica Ryle, ${ }^{18}$ debemos tener cuidado en no confundir el uso (use) con el empleo (usage). El empleo es un asunto relativo al estudio de hechos, cuya consideración debe quedar encomendada a quienes hacen un diccionario. En cambio, el estudio sobre el uso no es un asunto de lingüística, sino de "lógica" - una lógica de nueva especie, que implica la visión pluralista de los juegos del lenguaje.

Así, pues, mientras que la escuela de Oxford participa en el acento prescriptivo que es característico de la teoría emotiva, no comparte el punto de vista irracional de ésta sobre el valor, sino que más bien inventa una nueva especie de racionalismo de pequeña escala. Ofrecemos observaciones fácticas 
como razones para conclusiones morales, y consideramos que hay unas razones mejores que otras. Las razones en las situaciones morales son no solamente morales, sino que son, además, también razones: no son nada más que morales $-\mathrm{y}$ en este respecto dicha escuela desarrolla el argumento esencial presentado por G. E. Moore-; y no son nada más que razones, es decir, no son mandatos - no tanto aguijonean como más bien guían, para emplear los términos de Falk-; ${ }^{19}$ de modo que, en tal respecto, esta teoría se opone a la doctrina emotiva. Pero no es una teoría cognoscitiva. Pues si bien reconoce razones, niega la Razón. Su "razón" en las situaciones morales es venta al por menor, y no venta al por mayor, diríamos parafraseando a Hall. ${ }^{20}$ Como Edel ${ }^{21}$ lo ha expresado certeramente, busca el valor en las situaciones, al igual que el científico empírico busca muestras en la naturaleza. Es una axiología más bien al modo de Linneo que al modo de Darwin; y lo es de un modo consciente $\mathrm{y}$ agresivo. No hay ningún problema fundamental en Etica, dice Toulmin; ${ }^{22}$ hay muchos problemas, y en esta disgregación en pedazos radica el progreso ético. Para Toulmin, ${ }^{23}{ }^{24}$ un juicio ético es un juicio que expresa que algo constituye una buena razón para actuar de una cierta manera. Insiste en que las razones pueden ser buenas o falsas, incluso si no dan una prueba lógica o científica de la rectitud de las acciones a las que se refieren. Fiel al principio axio-empírico de la escuela, Toulmin explora situaciones individuales de decisión, y distingue en ellas varias especies de "buenas razones". Sin embargo, incurre en generalizaciones: en la mayor parte de los casos una buena razón para elegir o aprobar una conducta es que ésta se halla de acuerdo con una máxima de comportamiento establecida. A cualquiera que pregunte ¿por qué estas razones son buenas?, "yo puedo replicar solamente preguntando a mi vez ¿qué clases mejores de razones podría usted desear?" ". Mackie ${ }^{25}$ replica que él desearía razones un poco menos convencionales.

Mientras que Toulmin analiza razones, Hare, Nowell-Smith y Rice analizan juicios. Según Hare, ${ }^{26}$ los juicios éticos constan de: a) un elemento descriptivo naturalista; $b$ ) un elemento prescriptivo análogo a un imperativo, aunque no idéntico a éste. Insiste en que de meras proposiciones indicativas, uno no puede nunca inferir conclusiones éticas, como preceptos; con lo cual trata de refutar igualmente la opinión naturalista y la doctrina de Moore, de que nuestros deberes pueden ser derivados de una indefinible propiedad no natural de bondad poseída por las consecuencias de los actos. Según Hare, la principal objeción contra el naturalismo es la siguiente: si identificamos el bien, ora en la esfera de la ética, ora en la esfera de las pinturas, por ejemplo, con una particular propiedad fáctica, entonces seremos incapaces de alabar o recomendar nada por virtud de tener esta propiedad; $y$, sin embargo, sucede que el sentido principal de decir que algo es bueno es precisamente alabarlo o recomendarlo. Hare insiste en que esta objeción nada tiene que ver con la moral en particular, sino que es debida al carácter general de las palabras 
expresivas de valores. Las frases que atribuyen bondad a algo, si bien no son prescriptivas en el mismo sentido directo que las frases normativas, están cerca de éstas, pues su propósito es siempre orientar la elección, al menos indirectamente. Cierto que la palabra "bueno" puede ser usada descriptivamente: cuando hemos decidido cuáles son las características por las que alabamos o recomendamos un cierto tipo de cosa, podemos usar la palabra "bueno" simplemente para expresar que el objeto al cual es aplicada posee esas características fácticas; pero este uso puramente cognoscitivo es derivado y secundario. Para Hare los juicios éticos sobre nuestros actos futuros son decisiones; y esto hace difícil dar una explicación que admita la posibilidad de que uno vaya voluntariamente en contra de su propio juicio ético. NowellSmith ${ }^{27}$ adopta un punto de vista bastante similar al de Hare. Arguye que no podemos deducir que debemos hacer algo, partiendo de caracteres objetivos no naturales, del mismo modo que no podemos deducirlo partiendo de caracteres naturales. La terminología objetivista supone que hay comprobaciones con las que estamos de acuerdo. Ahora bien, sucede que tales comprobaciones no existen en el campo de la ética, por lo cual no podemos aplicar a éste los términos "correcto" y "equivocado", "verdadero" y "falso". Para Nowell-Smith, al igual que para Hare, los juicios de deber ser sobre las propias acciones de uno son decisiones o elecciones; y de esto deriva la conclusión de que hay algo muy extraño desde el punto de vista lógico en no hacer lo que pienso que yo debiera hacer, y análogamente en no escoger lo que reputo como mejor. El sentido del "deber ser" varía ampliamente según el contexto, y no puede ser reducido a'ninguna función singular, ni siquiera confinándonos al "deber ser" característicamente moral. Rice ${ }^{28}$ da un paso más allá hacia una mayor precisión y determina una única propiedad como aquella que todos los juicios de valor confirman -que es precisamente la que Hampshire ${ }^{29}$ destaca como el fuego fatuo de aquellos que andan a la caza de definiciones en el campo de la ética, a saber: "promover el mayor bien general". Rice no le tiene miedo a las definiciones. "El campo normativo no es caótico." El principio utilitario es la "propiedad identificadora" (PI) que se afirma de las acciones por todos los juicios de obligación moral; tal principio no es meramente una razón en pro de esos juicios, sino que es una parte constitutiva de su sentido primario. Rice analiza este sentido distinguiendo en él dos partes: un aserto de que el juicio posee la propiedad identificadora (PI); y un sentido matriz, o "SM", que es prescriptivo y se refiere a la realización del PI: “¡Hazlo!” Así, pues, la frase "A es bueno" es equivrlente a: “A posee la PI; ‘SMl". Análogamente: "moralmente yo debiera hacer A" es igual a "A promueve el mayor bien general; ¡SMl". Cualquier proposición moral encaja dentro de este esquema. Si preguntamos ¿pero por qué se debe promover el bienestar general?, Rice, a diferencia de Toulmin, no nos reta a dar una mejor fundamentación de la ética, sino que nos devuelve intacto el pro- 
blema. En última instancia, los principios normativos "no pueden ser plenamente justificados en un libro. Hasta el punto en que sea posible una justificación, ésta es finalmente llevada a cabo en el calor de la vida al rojo vivo". Dejemos que la conciencia sea nuestro guía. La conciencia es el “agente final para la vindicación de los principios que otorgan validez" al valor.

Un paso más allá hacia el conocimiento axiológico -y casi hasta el umbral de la racionalidad- lo da Feigl, ${ }^{30}{ }^{31}$ quien, análogamente a la justificación en el campo cognoscitivo, sugiere que los juicios morales tienen que ser reconstruidos como pretensiones de conocimiento, y como sometidos a validación o invalidación por virtud de su acuerdo o de su discrepancia respectivamente con las normas supremas de un sistema ético dado. Mientras haya muchos sistemas éticos, es fútil criticar un sistema de normas desde el punto de vista de otro sistema que es lógicamente incompatible con aquél. Este punto de vista es similar al elaborado con gran detalle por Lanz, ${ }^{32}$ unos diez años antes. Mientras que Lanz tiene que ser considerado como un cognoscitivista en materia axiológica, por razón de su insistencia sobre las dimensiones invariables de todos los cuadros axiológicos de referencia, en cambio, Feigl, que carece de este acento unificador, no es un cognoscitivista por entero, aunque se acerque a ello. Esto aparece también en su modo de tratar la objetividad. Según Feigl, la “objetividad” en el campo moral puede significar cualquiera de ocho aspectos diferentes que él especifica; pero no dice cuál de estos aspectos debe ser aplicado, si es que debe serlo alguno.

\section{Cognosctitvistas}

Cognoscitivistas son aquellos que asienten a las proposiciones 1), 2) y 3) - de las especificadas más arriba en la pág. 107-, es decir, son los que afirman que hay valor, que el valor puede ser conocido, y que el conocimiento consiste en sistematización. Por lo tanto, los problemas generales de los cognoscitivistas se refieren, desde el punto de vista positivo, a la epistemología y a la ontología del valor, y desde el punto de vista negativo, a la crítica de la posición semi-cognoscitivista. Por lo que se refiere a la epistemología del valor, la cuestión principal es la de cómo se pueden conocer objetivamente los valores. En lo que atañe a la ontología, el problema principal es qué clase de cosa sea el valor, especialmente, si es algo natural o algo no natural.

Kneale, Gilman y Negley abogan por objetividades que pueden ser llamadas respectivamente: formales, morales y epistemológicas. Kneale ${ }^{33}$ encuentra una objetividad en la ley moral definida como un conjunto de mandatos, que todos los hombres razonables, que poseen la información relevante, deben coincidir en darse a sí mismos y a sus prójimcs. Gilman ${ }^{34}$ aboga por una objetividad moral, en el sentido de autocrítica e imparcialidad, y la 
distingue de, la rectitud. Se puede ser objetivo desde el punto moral y, sin embargo, incorrecto. Negley ${ }^{35}$ defiende una objetividad epistemológica. Los datos fundamentales de la experiencia moral han sido considerados erróneamente como condiciones subjetivas del sentimiento, único e incomunicable, y no describible en ningún lenguaje. De tal guisa, la ética, por causa de una observación deficiente de su tema, se ha convertido en impotente para comunicar, y se ha deformado convirtiéndose en un ejercicio epistemológico. Contra esto Allers ${ }^{36}$ sostiene que la exclusividad y unicidad de un tema no implica necesariamente que la teoría que se ocupa de él sea incomunicable. La experiencia del color es única y personalísima, pero esto no ha impedido que los físicos desenvuelvan una espectroscopia. Aun cuando los valores pertenecieran a la clase de experiencias que sostienen los intuicionistas, seria posible desarrollar una ciencia objetiva de la axiología.

Kecskemeti y Prior han tratado problemas metodológicos y lógicos relacionados con la controversia entre los naturalistas y los no-naturalistas. Kecskemeti ${ }^{37}$ dice que los no-naturalistas son, en efecto, los más "científicos", pues buscan el fenómeno del valor como tal, al revés de lo que hacen los naturalistas que se mueven en toda suerte de direcciones que no tienen nada que ver con el valor. "Son los naturalistas quienes parecen desempeñar el papel de utopistas con los ojos en blanco, mientras que, por el contrario, los antinaturalistas se presentan más bien como temerosos conservadores que creen solamente en lo que ven y en lo que experimentan de modo efectivo." Según Prior, ${ }^{38}$ ni la posición naturalista ni la no-naturalista pueden ser demostradas. Mientras no haya una definición de lo "natural" o de lo "no-natural", que se aplique a las características, el naturalista podrá definir lo "bueno" como la propiedad natural X (p.e., "agradable") sin cometer una falacia, siempre $y$ cuando no sostenga que lo que está haciendo es Etica -sino más bien Hedónica o algo parecido-, o bien explique por qué y en qué respecto lo que hace es Etica. Pero lo que no puede hacer es servirse un pastel naturalista y tratar de comer también Etica. Contra tales naturalistas incongmentes $-\mathrm{y}$ la mayor parte de los naturalistas son incongruentes-- el argumento de Moore sobre la "falacia naturalista" es válido, observa Prior. Por otra parte, el argumento de Moore no impide desde el punto de vista lógico una ética naturalista. El no-naturalista no puede refutar al naturalista mediante simples asertos, como tampoco el naturalista puede refutar al no-naturalista sirviéndose de un procedimiento análogo. Así, pues, lo que ambas partes necesitan es una labor de definición -precisamente algo que la Escuela de Oxford excluye por principio. Por lo tanto, según esta escuela, la controversia es insoluble. Sin embargo, esta controversia podrá resolverse, tan pronto como se suministre una definición.

Las críticas contra la posición semi-cognoscitivista, especialmente contra la Escuela de Oxford, son principalmente dos: 1) la irrelevancia que sus jue- 
gos de palabras tienen para la realidad moral; y 2) la ilegitimidad de su intento de parar la investigación en el plano descriptivo. Rickman ${ }^{39}$ ataca su "tenaz querer evitar todo planteamiento sistemático", lo cual conduce a un "tortuoso afán discursivo, a coleccionar anécdotas triviales", y no lleva a conclusiones claras. Resignarse a una variedad y complejidad irreductibles de enunciaciones morales "puede conducir solamente al obscurantismo". Si hablamos de tales enunciados considerando que forman una clase, entonces debemos esperar que esta clase posea unas notas características propias. Ahora bien, estas características de los principios morales son las que señaló Kant. Lo que determina el carácter moral de las situaciones concretas - punto crucial de este tema- es que son aplicaciones de un principio moral. Según Rickman, esta interpretación resuelve la confusión fundamental en que incurren los semi-cognoscitivistas formalistas, a saber, la de los fines y las funciones lingüísticas de las enunciaciones morales. Ferrater $\mathrm{Mora}^{40}$ da una profunda caracterización de la dirección subyacente de tipo wittgensteiniano de esta escuela: "En última instancia, la tendencia del 'pensamiento' de Wittgenstein fue la supresión de todo 'pensamiento'." El pensamiento según Wittgenstein no sólo perturba la existencia humana, sino que es, además, una enfermedad; y el remedio no es otro método filosófico, sino una "terapéutica" filosófica. "Las cuestiones no deben resolverse, sino disolverse." También Sócrates se llamaba a sí mismo terapeuta. Pero su método era exactamente el opuesto al de Wittgenstein. El método de Sócrates consistía en agitar el malestar intelectual, para poner la mente en situación parturienta y hacerla dar a luz el concepto. El método de Wittgenstein consiste en poner fin al malestar, en enterrar el concepto. Si el método de Śćrates era mayłutico, en cambio, el de Wittgenstein puede ser llamado taféutico o funerario, el método propio no de la comadrona, sino del sepulturero. Observa Ferrater Mora que Wittgenstein es el Anti-Sócrates. Esta comparación con Sócrates proporciona la explicación del fracaso de los semi-cognoscitivistas en dar cuenta de la realidad moral. El conocimiento de la naturaleza se desenvolvió gracias a los métodos de Sócrates y Platón: "Nada es más impresionante", escribe Whitehead ${ }^{41}$ "que el hecho de que a medida que la matemática se fue retirando más hacia las regiones superiores de los más grandes extremos del pensamiento abstracto, regres 6 a la tierra habiendo adquirido un correspondiente aumento de importancia para el análisis de los hechos concretos. La historia de la ciencia en el siglo xvII se presenta como una especie de realización viva de un sueño de Platón o de Pitágoras."

Los cognoscitivistas plenos que aceptan las proposiciones 1), 2) 3), 4) y 5) (formuladas más arriba en la pág. 107) sostienen que el conocimiento de la naturaleza moral se encuentra en la misma dirección. Por lo tanto, consideran fundamentalmente errónea la opinión sostenida por la escuela "terapéutica" de que el conocimiento completo radica en lo más concreto. 
1) Naturalistas. De las dos escuelas cognoscitivistas, la naturalista y la no-naturalista, la primera está más cerca de los semi-cognoscitivistas. La posición naturalista padece, desde su misma base, la incongruencia señalada por Prior ${ }^{38}$ así como sufre también el prejuicio que contra lo abstracto tienen los semi-cognoscitivistas; pues también los naturalistas creen que el conocimiento concreto se halla mediante el análisis de las situaciones concretas. Así, pues, los naturalistas aceptan las proposiciones 1), 2) y 3) (pág. 107), pero rechazan las proposiciones 4) y 5). Consideran que la sistematización es inductiva y empírica, y que no puede ser deductiva y a priori. Se puede dividir a los naturalistas en dos grupos: los empiristas - que intentan hallar el valor en el contenido o materia- y los formalistas, que tratan de hallarlo en el método de las ciencias naturales.

a) Naturalistas de tipo empirista. El tratado más comprensivo y fundamental sobre esta materia es el de Edel, ${ }^{42}$ quien estudia las relaciones entre las ciencias sociales y la ética. Cree que la ética no puede alcanzar una sistematización más estricta que la lograda por las ciencias sociales. Mientras que el estudio que Edel hace de todo el campo de las ciencias psicologicas y sociales deja abierto el concepto de valor, Glansdorff, ${ }^{43}$ después de haber realizado un examen similar, desemboca firmemente en una ciencia como indicativa del lugar del valor. El valor es una calificación general de cosas que no son indiferentes. Esto presupone, en primer lugar, la representación mental de un objeto, $y$, en segundo lugar, el hecho de que somos afectados por el objeto. El análisis de las cualidades afectivas de la conciencia conduce a Glansdorff al resultado de que la teoría del valor no es más que una parte de la teoría biológica de la adaptación.

Mientras que Glansdorff ve el puesto del valor en la conciencia de la adaptación, Carlberg ${ }^{44}$ lo halla en la conciencia moral humana, entendida psicológicamente. Cimienta su obra sobre las investigaciones psicológicas de Maslow - que fueron recogidas en un volumen ${ }^{45}$ después de la aparición del ensayo de Carlberg-, y las desarrolla filosóficamente. Aunque el valor en cuestión es más bien ético que general -el valor del hombre es su autorrelación o autocumplimiento físico-espiritual-, posee adicionalmente un sentido axiológico general en el enfoque racional del problema. Otro enfoque del mismo problema es el ofrecido por W. Wolff. ${ }^{46}$ Wolff resuelve el problema de la característica de unicidad en la conciencia de valor de cada persona, centrando la atención en el cuadro singular de referencia que da a cada incidente en la vida de un individuo su posición y su sentido dentro del conjunto de ese cuadro o pauta individual. Sobre la base de esta psicología del valor, Wolff formula una terapia mediante la cual un individuo descubre su propia pauta axiológica y re-crea sus valores. En cuanto a la axiología, este estudio requiere una comparación con la importancia que la "terapia positivista" tenga 
para la experiencia de los valores. Requiere también una comparación con las teorías axiológicas de base psicológica propuestas, por ejemplo, por Ossowska $^{47}$ y B. Russell, ${ }^{48}$ y con las teorías de los valores basadas en varios aspectos de la experiencia psicológica -fenomenológico, teleológico, hedónico- como son las de Mandelbaum y Hilliard.

Mandelbaum ${ }^{49}$ enfoca el problema del valor examinando los juicios morales mediante un análisis empírico - "fenomenológico", "estructural", "situacional", "contextual". Considera que la determinación de la diferencia que indica cuál sea la clase de juicios morales consiste en una tarea de análisis más bien situacional que semántico o sintáctico. El rasgo que todos los juicios morales poseen en común es el hecho de que un juicio moral directo constituye siempre una respuesta a una demanda objetiva de que la situación ante mí debiera ser completa precisamente de este modo y no de otro. Los juicios morales directos se hacen, y solamente se hacen, cuando capto una situación como algo que es incompleto y requiere una cierta acción de mi parte para completarlo. Esta adecuación de la respuesta es lo que se significa con las palabras "justo" y "bueno". La teoría de Hilliard ${ }^{50}$ es la doctrina más concienzudamente elaborada sobre la base de una especial definición empírica del valor. Tal vez esta doctrina no se halla de acuerdo con la norma de parsimonia que debe regir la producción de teorías tan detalladas como ésta, basada solamente en un aspecto particular del valor; $y$ el hecho es que la dificultad teórica fundamental va apareciendo en la complejidad progresiva de este trabajo. Pero esa teoría de Hilliard aporta una profunda visión de los más diferentes fenómenos de valor - lo cual prueba que cualquiera que sea la teoría que se elija, no puede por menos de lograrse resultados apreciables si se desenvuelve esta teoría con suficiente extensión, y se la ensaya y escudriña con suficiente profundidad. La base del enfoque de Hilliard es el hedonismo psicológico egoísta. Sobre esta base, define el valor como la afectividad que se produce en la contextura relacional determinada por la reacción de un organismo a un objeto estimulante. Por otra parte, la utilidad es una característica predicable de todo objeto que posea la potencialidad de ser medio al servicio de un fin para un particular organismo. Entre utilidad y valor no se da una necesaria relación recíproca. Un objeto puede poseer utilidad y no ser valorado, o puede ser valorado pero no en términos de su utilidad. Hilliard distingue rigorosamente entre valor intrínseco y utilidad, por una parte, y entre valor terminal y valor instrumental, por otra parte; es decir, distingue entre axiología y teleología. El sentido del término "bueno" deriva del sentido del término "valor", entendido como "valor positivo". "Bueno" es el adjetivo general predicable de todos los objetos que ocasionan una afectividad positiva, cuando forman una contextura relacional con cualquier organismo.

La teoría de Hilliard es una obra axiológica que no. solamente es natu- 
ralista en cuanto al método usado, sino también en cuanto al contenido al cual se aplica dicho método. Esto habrá de ser así en todas las obras naturalistas que realicen fielmente su programa. Pero, hasta el presente, la doctrina de Hilliard es la única obra completa de esta especie. Sin embargo, hay un número de otros ensayos que proponen la aplicación del método científico a los objetos axiológicos, concibiendo éstos como objetos de la ciencia natural. Entre ellos, recordemos los siguientes: los ensayos de Kraft, Northrop, Rapoport, Davidson et al. y Braithwaite. Kraft ${ }^{51}$ intenta un análisis lógico-psicológico como fundamento para una "teoría científica del valor". Para Northrop, ${ }^{52-59}$ los valores no son más que ciertas implicaciones y aplicaciones de la ciencia natural. Expresándolo simplemente, el valor moral, por ejemplo, concierne al hombre, y el hombre es lo que la ciencia natural dice que él es. Así, pues, el bien para el hombre depende de lo que la ciencia natural dice. Entonces la cuestión consiste en saber qué es lo que la ciencia natural dice y cómo lo dice. Northrop toma como punto de partida el meollo mismo del método científico, la distinción de Galileo entre cualidades primas y secundarias, y la extiende hasta llegar a la distinción entre dos componentes de la vida cultural: el teórico y el estético. La relación entre estos dos componentes, según Northrop, es una relación entre dos términos, que él llama la "correlación epistémica", la cual consiste en la correlación de la teoría científica (el componente teórico) y las observaciones empíricas (el componente estético). No sólo los objetos científicos, sino también cualesquiera otros que puedan ser conocidos, presuponen la correlación epistémica. Por lo que se refiere al bien moral, puesto que el hombre y la naturaleza aparecen de modo diferente según cuál sea la correlación epistémica en las diferentes culturas, así también el bien para el hombre, y el hombre bueno, aparecerán de modo diferente según cuál sea esta misma correlación. Así, pues, resumiéndolo en una fórmula, bueno para la cultura es lo que es verdadero para la naturaleza en esa cultura.

Rapoport ${ }^{\text {e0 }}$ propone una "ética operacional", que descansa sobre la premisa de que las normas de conducta y las metas no deben ser fijadas a priori, sino surgir como el resultado de una investigación. Los valores son las necesidades constantes o invariantes del hombre. Desde el punto de vista operacional, los fines básicos constantes del hombre no están sujetos a una discusión ética -la cual versa sobre el elegir-, porque no tenemos elección, ya que no cabe otra cosa más que perseguir la realización de tales fines. Sin embargo, esos fines pueden determinarse por medio de una investigación científica, al igual que de este modo pueden determinarse los medios fisiológicos. El método para reducir la ética a ciencia es, pues, reducir a un minimum el número de los fines que escojamos. Las metas constantes o invariantes en última instancia son el objeto final de la ética $-\mathrm{y}$ al llegar a ellas la ética deja de ser ética, para convertirse en ciencia natural.

b) Naturalistas de tipo formalista. En lugar de cercenar el número de 
fines posibles para evitar contradicciones entre ellos, se podría proceder a la inversa, y hallar un cuadro general de referencia que diese cuenta y razón de todas las clases posibles de procesos de preferencia. Este es el método de Davidson, McKinsey y Suppes. ${ }^{61}$ Estos autores siguen el método axiomático de la ciencia. Su teoría del valor es formalista; $y$, puesto que está basada en un fenómeno naturalista, el del elegir o escoger, es una doctrina naturalista de tipo formalista. Por otra parte, según ellos, la elección no es un tema de la ciencia natural, como lo es para Rapoport, sino que pertenece a un cuadro de referencia sui generis, producido ad hoc. Por consiguiente, este cuadro de referencia no es constructivo o sintético en el sentido de que él defina su propia materia, la elección, de un modo autónomo como lo hacen las teorías en la ciencia física, sino que es abstractivo o analítico, y elabora su tema de manera sistemática. Se trata, pues, de una teoría empírico-formal, similar en cuanto al método a la de Hilliard, pero mucho menos rica de contenido que ésta. Ahora bien, no es una teoría formal a priori. Es una especie de meliorismo. Mientras que el meliorismo no-naturalista se basa en la noción de perfeccionamiento, el meliorismo naturalista, en cambio, se funda sobre la relación de preferencia. En sus tres formas lógicas - $\mathrm{X}$ es preferida a $\mathrm{Y}, \mathrm{Y}$ es preferida a $\mathrm{X}, \mathrm{X}$ es igual en preferencia a $\mathrm{Y}$-, cabe elaborar pautas de preferencia, las cuales, usando consideraciones de probabilidad, pueden ser construidas en progresión más y más alta. Mientras que Davidson et al., aplican consideraciones estadísticas a los problemas de valores, Braithwaite ${ }^{62}$ aplica consideraciones de valor a los problemas estadísticos. Cree que tales consideraciones determinan en alguna medida la elección entre hipótesis estadísticas, y que de esta guisa lo ético "irrumpe" dentro de la lógica inductiva. Por otra parte, aplica cálculos de probabilidad al problema de la elección y de la preferencia, ${ }^{63}$ aplicando la geometría de las parábolas, y ofreciendo de esta suerte "una pequeña contribución hacia la realización del ensueño de Condorcet déclairer les Sciences morales et politiques par le flambeau de lAlgèbre”.

No todas las teorías naturalistas de tipo formalista son tan precisas ni están tan elaboradas, pero todas tienen en común la aplicación del método científico -concebido con mayor o menor rigor - a los objetos de valor, los cuales, aunque sean concebidos al modo naturalista, son no obstante diferentes de los objetos de las ciencias de la naturaleza. Margenau ${ }^{64}{ }^{65}$ es más preciso en pedir una axiología que se desenvuelva por la vía del método de las ciencias naturales, pero cuyo contenido, en cambio, no sea del tipo que es propio de las ciencias de la naturaleza. Si la ética, y en general la teoría de los valores, ha de poseer una metodología, puede suponerse que dicha metodología habrá de ser semejante a la de las ciencias de la naturaleza. Por otra parte, es imposible deducir por secuencia lógica las normas de ninguna ética partiendo del contenido de una ciencia. Mientras que Margenau ofrece explícitamente indicaciones para una axiología científica, la cual, sin embargo, no 
es una ciencia de la naturaleza, Raphael ${ }^{66}$ ofrece ya un esquema de una axiología tal, o por lo menos de una ética de este tipo. Raphael asigna a la ética, desde el punto de vista de la filosofía moral, la misma tarea que Margenau le señala desde el punto de vista de la filosofía de la naturaleza. Su sistema no es tan formal como un sistema lógico. La diferencia entre estas dos características, como él mismo apunta, es la siguiente: la lógica de la moral, de modo diverso a lo que sucede con la lógica formal, toma en consideración el contenido de los conceptos y de los juicios, y no meramente formas vacías, de tal suerte, que es una aplicación de la lógica formal a un especial campo del pensamiento; por lo tanto, no es simplemente lógica formal. A pesar de esto, el sistema de Raphael constituye uno de los pocos intentos de aplicar la estructura lógica a la filosofía moral. Sus términos fundamentales, aunque en alguna manera parezcan categorías kantianas en cuanto a su poder implicativo, sin embargo no son tales categorías; no lo son porque, en parte, Raphael no las construye de esta manera, $y$, en parte, porque dichas categorías carecen del alcance sistemático que las categorías kantianas derivan de su deducción lógica. $O$, expresado con otras palabras, no hay una conexión explícita entre la lógica de la moral y la lógica pura y simple.

Algo análogo puede decirse de otros intentos en la misma dirección, como los de Mc Cracken, Stofer y Kecskemeti. Según Mc Cracken, ${ }^{67}$ el valor es explícitamente una categoría del entendimiento, análoga a la categoría kantiana de causalidad. La proposición " $\mathrm{x}$ es rojo" sólo gramaticalmente es similar a la proposición " $x$ es bueno". La diferencia no radica en el hecho de que "bueno" sea solamente un predicado emotivo, mientras que "rojo" es una simple cualidad "dada" al sensorio. La diferencia consiste más bien en el hecho de que cuando digo " $\mathrm{x}$ es bueno", caracterizo la situación total en la que aparece $x$. Si la idea de valor se puede tomar como una categoría de inteligibilidad, análogamente a la categoría fáctica de causa, entonces, dice Mc Cracken, las teorías de los valores pueden contribuir al conocimiento con verdad no menor que las teorías de la causación física. Ahora bien, aun cuando esta doctrina de Mc Cracken sea superlativamente sugestiva, sigue habiendo en ella la ya mencionada falla en lo que se refiere a la analogía con una categoría kantiana, a saber: Kant dedujo de la lógica sus categorías, y así pudo darles una pauta o estructura sistemática, por virtud de la cual su función epistemológica era no sólo universal, sino también precisa. Este rasgo esencial de la categoría kantiana falta en la explicación de Mc Cracken, y limita la aplicabilidad de su teoría a la realidad axiológica. La índole categorial del valor no debe ser simplemente enunciada: debe ser deducida de la lógica o de algún otro sistema que le dé alcance sistemático.

Stofer ${ }^{68}$ considera la valoración como una función fundamental del hombre. Así como el conocimiento contiene una variedad de categorías ordenadoras, tales como las de espacio y tiempo, que hacen posible delimitar y com- 
prender objetos, así la valoración depende de una variedad de factores de la experiencia, los cuales capacitan para una selección entre los modos posibles de reacción. Kecskemeti ${ }^{37}$ intenta una explicación racional del desacuerdo en materia moral, no de modo exactamente igual al de Braithwaite, sino por medio de una especie de enfoque categorial, usando la categoría de imparcialidad. Hablando en términos lógicos, el principio de imparcialidad es un postulado. Es racional de la misma manera y por la misma causa que lo son los postulados básicos de la actividad científica.

Todas estas obras plantean en principio la cuestión sobre la base racional de los juicios de valor. Lewis ${ }^{69}$ trata de descubrir una pauta racional para los juicios de valor en el razonamiento inductivo. Ewing $70{ }^{71}$ está convencido de que, aun cuando la ética posea una lógica propia, esta lógica no es muy diferente de la lógica ordinaria. Baylis ${ }^{72}$ muestra que algunos juicios de valor - los que afirman que el carácter agradable de una experiencia es bueno-, pueden confirmarse hasta cierto punto por la vía empírica mediante la cual son confirmados los juicios científicos. Wick ${ }^{73}$ sostiene que podemos considerar las normas morales como criticables racionalmente, pero formulables imperfectamente, de una manera similar, a aquella en que "criticamos y tratamos de enunciar las reglas genéricas de la lógica”, como por ejemplo, el principio de contradicción. "Si hay algo que sea racional, estos principios son racionales; y, sin embargo, no son cognoscibles." Así, pues, hay una diferencia entre lo racional y lo cognoscible; y no todo lo que no es cognoscible es emotivo. Las reglas máximas morales, así como los principios que las rigen, tienen fundamentos racionales. Análogamente Urmson ${ }^{74}$ sostiene que no hay razón para condenar el razonamiento ético simplemente porque no sigue las reglas establecidas ni por la lógica deductiva ni por la inductiva. Es tan imposible que todos los argumentos éticos sean inválidos, como lo es que todos los hombres sean pequeños. Si hubiese alguna lógica que condujera a este resultado, tanto peor para esa lógica. Según Paton, ${ }^{75}$ la teoría emotiva desacredita a la ética: la actitud moral es esencialmente racional. Para Mabbott, ${ }^{76}$ el análisis subjetivista de los juicios morales es contrario al uso normal. Las "significaciones" que ese análisis les atribuye no son las que auténticamente tienen dichos juicios morales. Cuando comparamos juicios morales diferentes, empleamos procedimientos que implican una objetividad.

La dificultad general para establecer un sistema axiológico independiente con validez universal, y que posea el mismo rigor que el sistema matemático de las ciencias de la naturaleza, ha llevado a algunos axiólogos a aplicar a la estimativa la terminología y el método de las ciencias axiológicas ya existentes. Así, Lamont ${ }^{77}$ basa su análisis del juicio de valor en la terminología y en los procedimientos de la ciencia económica, de un modo similar, aunque más sistemático, al que había empleado antes ${ }^{78}$ al relacionar el juicio moral con la jurisprudencia. 
Banfi, ${ }^{79}$ Lacroix $^{80}$ Znaniecki $^{81}$ y Straus ${ }^{82}$ basan su teoría moral en las teorías generales de la cultura. Geiger ${ }^{83}$ ofrece un estudio general sobre los valores y el cultivador de las ciencias sociales; y Lepley ${ }^{84.85}$ ha compilado y sacado a luz un simposio sobre la relación general entre los juicios de valor y los juicios científicos, que contiene dos investigaciones paralelas y en cooperación. Los colaboradores a la primera investigación concuerdan en una interpretación empírico-naturalista de los fenómenos de valor, si bien no consideran tales fenómenos como idénticos a aquellos estudiados por las ciencias de la naturaleza. Están en pro de la aplicación a los valores del método de las ciencias de la naturaleza - concebido empíricamente- pero, en cambio, no propugnan lo mismo respecto de su contenido. Las colaboraciones a la segunda investigación cubren toda una gama desde la interpretación empírica hasta la construcción formalista del lenguaje valorativo.

\section{No-naturalistas}

A) No-naturalistas de tipo empirista. Los no-naturalistas de tipo empirista son aquellos que reconocen el valor ora en una experiencia ontológica, ora en una experiencia fenomenológica. En el primer caso, el valor aparece como un aspecto del Ser; y en el segundo, como un reino aparte.

a) Ontologistas. A este tipo pertenece la doctrina escolástica del valor, que ha tenido recientemente un representante en Leclercq. ${ }^{86}$ Este autor ofrece una exposición y desarrollo de esta doctrina - sobre el valor en general, la noción del bien, de la verdad y de la belleza (en el sentido de transcendentales ) - en un estudio que, por su claridad y estructura lógica, ofrece mucho a la teoría de los valores contemporánea, que se halla en una situación caótica. Aclara el impresionante parecido - así como también la diferencia- entre el método escolástico y el moderno en el enfoque de la noción del valor, a través de un análisis lingüístico del lenguaje corriente. El método escolástico, análogamente al moderno, halla el aspecto fundamental de la moralidad en el juicio de valor; pero, en lugar de inventar una nueva "lógiça" de "sentidos" contextuales, usa el método clásico de Sócrates, Platón, Aristóteles y Santo Tomás. Este método consiste en examinar el sentido habitual de los juicios cotidianos de valor, $y$, una vez hallado este sentido, en elevarse a los conceptos a los cuales corresponden tales sentidos y a la idea de realidad que esos conceptos implican. Así, pues, aquí, al igual que en el procedimiento científico usual, que es empírico, uno se eleva de lo particular a lo universal. El caos y las contradicciones de las palabras y frases corrientes se superan mediante el método de llegar, como en una precipitación científica, a la médula de todos los materiales, y de formular esta médula en una definición. Este método se ha perdido en muchas teorias contemporáneas sobre el valor. Sucede que, cual ocurre por ejemplo en la escuela de Oxford, muchas teorías se quedan en "sentidos" fragmentarios, sin desear un análisis total y exhaustivo, o 
enuncian nociones universales sin anclarlas en el uso cotidiano. Según Leclercq, entre todas las escuelas contemporáneas, sólo la fenomenológica sigue la tradición.

En vista de la claridad lógica de esta escuela, tiene especial importancia el ver a dónde conduce su método. Conduce, en suma, a una ontología de los valores que puede ser expresada en muchas formas, además de aquella en que aparece en sus propios términos metafísicos. Hablando en sentido ontológico, la cosa es buena en el grado de su perfección. Cada cosa posee su propio orden de perfección. La bondad del caballo no es lo mismo que la del pan, y la bondad de un caballo de carreras no es lo mismo que la de un caballo de tiro. Así, pues, el juicio de valor depende de la naturaleza de la cosa juzgada. Esta terminología metafísica puede expresarse de diferentes maneras. En términos modernos, significa que la cosa es buena si tiene las propiedades determinantes de su valor. En términos aristotélicos, significa que la cosa es buena si cumple su propósito. Hablando en términos epistemológicos, significa que la cosa es buena si tiene sus propiedades esenciales. Hablando en términos lógicos, significa que la cosa es buena si cumple toda la comprensión de su concepto. Si pasamos revista a la historia de la axiología, advertiremos que aquí hay algo así como una axiologia perennis. Esta axiología lleva a la teología, cuando se generaliza la noción de perfección específica hasta convertirla en la perfección de un Ser Absoluto que no carece de nada y posee la abundancia de todas las propiedades.

Variantes de la doctrina ontológica del valor las encontramos en todos los países del Continente europeo, en América Latina y en Asia. En Francia tenemos las últimas obras de Lavelle ${ }^{87}$ y Le Senne, ${ }^{88}$ quienes consideran los valores como garantizados por una fuente trascendente, el Yo Absoluto, en el cual participan los yos finitos. Por otra parte, en Italia, la metafísica del valor, bajo la influencia de Croce y Gentile, subraya la inmanencia del valor más bien que su trascendencia, cubriendo toda la gama desde una inmanencia anclada en la dialéctica del espíritu a una inmanencia basada en la estructura de la situación concreta, concebida existencialmente e incluso naturalistamente. Croce $^{89}$ afirma que la categoría de "vitalidad" es una integración necesaria de las varias formas del espíritu, "el cual carecería de voz, de b́rganos y de poder, si... aquellas formas fuesen separadas de él". Según Gentile, ${ }^{90}$ quien estructura el acto espiritual de una manera más y más deontológica, la referencia de este acto al ser no es trascendente, sino que es inmanente: la valoración es asunto de la autoconciencia, nacida de la voluntad espiritual y coincidente con ésta. El carácter racional de la axiología idealista se ha conservado casi enteramente en los nuevos desenvolvimientos de la axiología en Italia. Cuando se ha renunciado a tal carácter racional, como ocurre en la obra de Ugo Spirito, ${ }^{91}$ entonces ese carácter ha sido reemplazado por un substituto que tal vez es incluso más apto para entender la vida moral, emparejándose 
con la más profunda sensibilidad para el problema ético. Dice Spirito que las premisas metafísicas de la filosofía occidental han conducido a un dogmatismo de juicios objetivos: quien juzga opone a sí propio la cosa juzgada, y de tal suerte la aparta de sí mismo y de una verdadera comprensión. La interpretación teórica que Gentile da del Acto debe ser substituida por una actividad creadora del espíritu, y la relación objetiva debe ser reemplazada por un nuevo tipo que supere la dualidad y tenga su base en el amor y la solidaridad entre el hombre y las cosas -la misma problemática que hallamos en la ética de Buber, ${ }^{92}{ }^{93}$ en su distinción entre la relación yo-ello y la relación yo-tú, y en la lógica de Husserl. La suspensión del juicio cancela la particularización de lo individual, devuelve su valor original a cada aspecto de la realidad e impide la formación de una jerarquía abstracta de perfecciones (Cf. Le Senne). Los análisis del valor llevados a cabo por Lazzarini y Abbagnano son más estrictamente fenomenológico-existenciales. Lazzarini ${ }^{94}$ influido por Kierkegaard y Husserl, ve la definición del valor en la propiedad del sujeto de hallarse abierto a las múltiples metas que implica la intencionalidad del acto espiritual. Abbagnano, ${ }^{95}$ en contraste con el negativismo del existencialismo alemán y con el espiritualismo del francés, introduce la categoría de posibilidad como norma de la experiencia y como ley ética. Posibilidad indica la estructura inestable y precaria de la experiencia y el carácter problemático de ésta. "Todo lo que llamamos valor y que da a la vida sentido y aroma -belleza, bondad, verdad- es inseguro y mutable." Esta teoría se halla ya lejos de las concepciones idealistas de Croce y Gentile. Tan sólo un paso más, y desembarcaremos en el contextualismo axiológico. Podemos considerar como una transición a éste la doctrina de Bagolini, ${ }^{96-98}$ la cual constituye una especie de emotivismo objetivado. De un modo original e ingenioso, Bagolini usa el mito como una categoría de la emoción y como una definición del valor. La cognición y la voluntad están condicionadas por una variedad de valores que son las proyecciones espontáneas de la conciencia, y pueden ser consideradas como mitos en el sentido de manifestaciones emocionales profundas de la vida humana. La realidad del valor-mito es irreductible a la racionalidad; es más bien una objetivación de lo emocional, una especie de actitud stevensoniana objetivada.

Mientras que los escritores mencionados en el párrafo anterior se desenvuelven por así decirlo cuesta abajo, desde el idealismo a situaciones humanas, en cambio, otros filósofos, como Battaglia, ${ }^{99.102}$, Sciacca, ${ }^{103.108}$ Capograssi ${ }^{109}$ y otros desarrollan el idealismo hacia arriba y anclan la moralidad en una relación con Dios.

También en el pensamiento español y en el hispanoamericano hallamos interpretaciones del valor vigorosamente ontológicas, no sólo en la corriente neoescolástica, sino también en la dirección existencialista, y asimismo en otros ensayos críticos sobre la teoría general del valor. A la corriente neoescolástica 
pertenecen las obras de Zaragüeta, ${ }^{110.112}$ Urdánoz, ${ }^{113}$ Oromí, ${ }^{114}$ Farré. ${ }^{115}$ A la dirección existencialista pertenecen Muñoz Pérez, ${ }^{116}$ Montero Moliner ${ }^{117} \mathrm{Al}-$ corta. ${ }^{118}$ En el grupo de quienes han producido ensayos críticos, figuran Linares Herrera' ${ }^{119}$ y Cencillo. ${ }^{120}$ Julián Marías ${ }^{121}$ ha dado una lúcida reelaboración del concepto de razón vital según Ortega y Gasset, con importantes implicaciones axiológicas. La vida humana es el sistema que se estructura a sí mismo y que funciona como razón vital: el yo es el órgano esencial de comprensión. La experiencia, no en el sentido epistemológico sino en el sentido existencial, es la matriz de la conceptualización. Así, pues, fundamentalmente la comprensión y la valoración son una y la misma cosa. La diferenciación de la experiencia en conceptualizaciones es al mismo tiempo la diferenciación de la valoración. El vínculo entre la visión existencial y la valoración ha logrado una expansión en la textura de la axiología existencial de Romano Muñoz, ${ }^{122}$ en fuerte oposición contra el nihilismo axiológico de Heidegger y Sartre. La metafísica, según Romano Muñoz, se convierte en ética: el punto universal de referencia de la filosofía no es abstracto, sino que es concreto; está basado en la relación existencial entre el yo humano y el universo. Esta culminación de la ontología en axiología se complementa $-y$ además se ahonda ${ }^{123}$ - en el pensamiento de Recaséns Siches, quien por su parte da un fundamento axiológico a la ontología. ${ }^{124}$ Según Recaséns Siches, la filosofía fenomenológica de los valores - de la que me ocuparé en la sección próxima- escinde con excesiva radicalidad el mundo axiológico separándolo del ontológico. En una zona más profunda hay una recíproca relación entre hechos y valores. Aunque el mundo de la realidad y el mundo de los valores constituyan dos categorías diferentes, formalmente independientes, sin embargo, el uno parece existir para el otro, y el otro para el uno. La axiología debe indagar la vinculación entre los dos reinos. Según Recaséns Siches, el valor no es meramente, como se había dicho, una categoría tan primaria como la categoría del ser, sino que el valor es una categoría aún más primaria que la del ser, es decir, más fundamental que ésta. La realidad primaria y radical es la vida humana, esto es, la compresencia del yo y su mundo. La conciencia, al actuar como una redecilla selectora, está condicionada por actitudes valoradoras. En el pensamiento de Recaséns Siches, pues, la axiología se convierte en la raíz profunda de la ontología —con un resultado que en forma naturalista lo hallamos también en Werkmeister. ${ }^{125.127}$ Pero mientras que Werkmeister da una interpretación psicologista del valor, en cambio, Recaséns Siches rechaza toda doctrina puramente psicologista. Los valores, dice Recaséns Siches, no son proyecciones o reacciones de los mecanismos psicológicos. En este sentido son objetivos, es decir, no son subjetivos. Ahora bien, se debe entender tal objetividad como inmanente a la vida humana, como una objetividad intravital. El hombre no crea los valores. Pero los valores son tales y tienen sentido dentro de la contextura de la vida humana. 
Por otra parte, la estructura de la vida humana está condicionada por valores. Así, en la teoría de Recaséns Siches hay un vínculo fundamental entre valoración y existencia humana. Nicol estudia esta conexión históricamente, en el más amplio contexto. ${ }^{128}$ Frondizi, ${ }^{128}$ bls aun cuando rechaza también las explicaciones meramente psicologistas, cree que no se puede separar radicalmente el valor y la valoración, y entiende que tanto el uno como la otra se dan en el contexto de situaciones concretas, en las cuales se combinan componentes subjetivos y componentes objetivos. Entre los elementos subjetivos figura la vida psicológica pasada, y la presente, la influencia del organismo, los nexos e influencias sociales y culturales. Entre los componentes objetivos hay dimensiones inherentes al objeto valorado, que lo hacen aparecer como valioso con independencia de las eventuales reacciones psicológicas que suscite.

En Alemania encontramos un nuevo retorcimiento, superlativamente inesperado de la dicotomía hecho-valor, entendida ontológicamente, en el nihilismo axiológico de Heidegger. ${ }^{129-130}$ Según Heidegger, la axiología no es otra cosa que un sucedáneo (Ersatz) de la metafísica del ser que perdimos. Dice que "pensar en valores es puro nihilismo". Puesto que valor y ser serían distintos, el valorar obstruiría el ser del ser si el valorar pretendiese superar al ser y tomar su puesto. "Pero si el valor no deja que el Ser sea el Ser, lo que el Ser es en tanto que el Ser mismo, entonces la supuesta superación es ante todo la consumación del nihilismo" "Wenn jedoch der Wert das Sein nicht das Sein sein lässt, was es als das Sein selbst ist, dann ist die vermeintliche Uberwindung allererst die Vollendung des Nihilismus"). Así, pues, el golpe más fuerte contra el verdadero valor - es decir, el ser- es valorar - y el golpe definitivo contra Dios es valorarlo. Dios "es degradado al hacerlo el supremo valor" ("zum höchsten Wert herabgewiirdigt"). Valorar a Dios, el Ser de los seres, como el valor de los valores es "la máxima blasfemia". Al igual que todos los falsos profetas, quienes hacen esto se disfrazan como sumos sacerdotes. "El no pensar el Ser se disfraza a sí mismo con la apariencia de representar el Ser de la manera más digna." De este modo, Heidegger da un matiz inmoral a lo que G. E. Moore llama la falacia naturalista, en su aspecto de confusión entre el ser y el valor. Según Heidegger, la comisión de esta falacia es una traición al ser.

Este "desenmascaramiento" de la valoración ha llevado a un vigoroso contraataque que desenmascara el "desenmascaramiento", e intenta aportar las razones que deben ser aducidas contra la dialéctica del nihilismo axiológico. En la vanguardia de este contraataque encontramos a von Rintelen, ${ }_{1}^{131.133}$ cuyo realismo axiológico, edificado sobre la base del pensamiento alemán clásico, ${ }^{134}$ especialmente de Goethe, irradia - contra las sombras de Nietzsche- la clara luz de aquella tradición filosófica germana. Se puede entender la realidad histórica del valor de un modo vertical y de un modo horizontal: de un modo vertical, en la dimensión de valor real (Real-Wert); de un modo 
horizontal, en la de valor ideal (Wert-Idee). Rintelen moviliza contra Heidegger toda la philosophia perennis, contra la cual Heidegger trató de dirigir su propio anti-orden. Otra contribución profundamente racional a la ontología de los valores es la de Krings, ${ }^{135}$ quien enraíza la Verdad en la Probidad o Integridad (Lauterkeit). La Probidad o Integridad, o sea la correspondencia entre la esencia y la existencia, es la dimensión ontológica de la Verdad. La correspondiente contraparte ontológica a la Falsedad es lo Demoníaco. Lo Demoníaco intenta erigir un anti-orden contra el orden ontológico, y realizar una no-esencia, una monstruosidad ontológica (Unwesen), bajo cuya luz la realidad aparece deformada, falseada, fuera de lugar, fuera de encaje, y terrible (ent-setzt). En esta concepción de Krings tenemos una profunda fundamentación de una futura lógica del valor, y de la racionalidad esencial del mundo de los valores. Dentro de la corriente de la tradición escolástica, hallamos una reafirmación de esta racionalidad en la introducción que Siewerth escribió a algunos textos de Santo Tomás de Aquino, ${ }^{136}$ y también en una obra de Gutwenger, ${ }^{137}$ que ofrece una original combinacion de elementos tomistas y naturalistas. El valor es siempre valor-para, valor relacional. Esta relacionalidad del valor es de índole causal, en el sentido de que la cosa o persona en cuestión está siendo perfeccionada (vervollkommnet). Entonces, la definición del valor es: causalidad perfeccionante (vervollkommende Kausalität).

Volviendo ahora la vista a la axiología oriental, nos hallamos con que su clima no es muy diferente de la metafísica europea de los valores. En la India, especialmente, encontramos una posición metafísica con una clara acentuación humanista, una especie de "pragmatismo trascendental". La axiología, búsqueda consciente de los valores (phala-präpti), es una de las dos partes de la filosofía india, mientras que la otra es el descubrimiento de los hechos (artha-paricchitti), la cual implica la primera. La base ontológica de la axiología india está sugerida por el sentido de la palabra sánscrita sat, la cual significa tanto lo "real" como lo "bueno", mientras que la dirección teleológica pragmática se expresa con el término bhavya, que denota tanto lo "futuro" como "lo que es favorable", lo cual sugiere que lo mejor está todavía por acontecer. El término sánscrito para designar el valor es ista: "el objeto del deseo"; y lo opuesto es dvista, "antivalor". El valor es aquello a lo cual aspiramos y cuya realización es posible, sãdya: lo que es "querido racionalmente". Lo que se desea y lo que debe ser deseado son ambos valores. Purusãartha significa "valores humanos": la persecución consciente de los valores por el hombre. Tanto el hombre como el animal buscan la satisfacción de sus impulsos naturales, pero solamente el hombre busca la satisfacción consciente de éstos. Puruśárthas son, por consiguiente, los valores perseguidos conscientemente, o sea los valores humanos. Esta construcción general ha sido elaborada en las obras recientes de Hiriyanna, ${ }^{138}$ Sri Jaya Chamaraja Wadiyar Bahdur, ${ }^{139}$ Ranga Swami, ${ }^{140}$ y otros. 
b) Empiristas Fenomenológicos. Los empiristas fenomenológicos sostienen que hay una experiencia cognoscitiva de un reino de valores sui generis, independiente $y$ diferente del reino ontologico del ser. Son axíblogos puros, en el sentido de que no confunden el valor con ninguna otra cosa, ni física ni metafísica. Entre ellos encontramos, además de la figura solitaria del británico G. E. Moore -cuya teoría ha hallado algunos seguidores, como Hill ${ }^{141}$ y Corkey, ${ }^{142}$ pero muchos críticos--, la tradición de Max Scheler y Nicolai Hartmann. Las doctrinas de ambos están contenidas en nuevas ediciones ${ }^{143}$ de sus obras, publicaciones póstumas, y en estudios monográficos sobre aquéllas, como los de Pavićevic, ${ }^{144}$ Mayer ${ }^{145}$ y Hürlimann, ${ }^{146}$ y han obtenido desenvolvimientos y aplicaciones muy importantes. Nicolai Hartmann ${ }^{147}$ nos da un análisis del pensar teleológico, como suplemento a su explicación del "triple nexo finalista", en la Etica, y una visión más profunda de la relación entre la voluntad y el sentimiento moral, la cual arroja luz sobre la difícil distinción - que no es posible en cualquier otra posición axiológica- entre lo emotivo.y lo valorativo. "El sentimiento del valor tiene una relación con el valor entéramente diferente de la que tiene la voluntad. La voluntad es libre con respecto a los valores, no está forzada a seguir el mandato moral. . . Por otra parte, el sentimiento del valor no es libre en este respecto; está claramente forzado por los valores: una vez que ha captado el sentido de un valor no puede... sentirlo de modo diferente o tomar una posición que no sea aquella que está determinada por el valor. No puede considerar la buena fe como mala, o el engaño y el fraude como honorables. Puede ser ciego para los valores, pero esto constituye un asunto por entero diferente: en tal caso, no responde a los valores, y no los entiende en modo alguno." 148

Además de las aportaciones de von Rintelen, Recaséns Siches y Marías, quienes en cierto modo y en alguna medida pertenecen también a esta corriente, hallamos ulteriores desarrollos de la posición fenómenológica en las obras de García Máynez, Reding, Vivas, Christoff y Widmer. García Máynez $\mathrm{z}^{149.151}$ desenvuelve la relación entre el reino del valor y el de las normas jurídicas. Reding ${ }^{152}$ y Vivas ${ }^{153}$ desarrollan la fenomenología axiológica en una dirección antropológica; y Christoff y Widmer la llevan más bien hacia una dirección existencial. En un estudio superlativamente agudo, ${ }^{154.156}$ Christoff se ocupa de la relación epistemológica entre el reconocimiento efectivo de un valor y la propia condición o situación fenomenológica del valor. Según Widmer, ${ }^{156} 157$ los valores no son producidos por nuestra conciencia, sino que son independientes de ésta. Por otra parte, los valores no pueden ser por entero trascendentes. Tenemos que decidir entre ellos; y para hacerlo, nunca será bastante escoger entre un determinado número finito de ellos, sino que más bien será preciso que nuestras almas estén abiertas al infinito y a sus posibilidades ilimitadas. A un resultado semejante llega Gauss a través de una aplicación de la jerarquía platónica de las ideas. ${ }^{158}$ 
B) Formalistas No-Naturalistas. El espectro que he presentado de la axiología contemporánea ha destacado semejanzas en el pensamiento sobre los valores a través del mundo, las cuales, si las tomamos en serio, sugieren una lógica subyacente del valor, tal como lo sostienen Ewing, con Rintelen y otros. Las agudas investigaciones ontológicas y fenomenológicas de pensadores como Krings y Christoff sugieren profundas y agudas diferenciaciones intelectuales en el reino del valor, las cuales pueden espejar distinciones de tipo formal tan rigorosas y precisas como las matemáticas. Las formalistas nonaturalistas intentan desarrollar ese tipo formalista de distinciones. Aceptan las cinco proposiciones originales que he presentado al comienzo de este trabajo, y creen que es posible construir un sistema axiológico formal que pueda ser aplicado a la realidad de los valores, análogamente a como la matemática se aplica a la realidad de la naturaleza. No todos los pensadores pertenecientes a este grupo tienen esta visión igualmente clara, pero ella se encuentra en todos en alguna medida, cuando no de modo explícito al menos implícitamente. Un caso similar tenemos con algunos pensadores de los que me he ocupado anteriormente, como Rickman, y su ingeniosa solución de la dicotomía emotiva-descriptiva, como surgida de la distinción lógica entre teoría y aplicación; como también en von Rintelen en su distinción entre Valor Real (Real-Wert) y Valor Ideal (Wert-Idee); como asimismo en Feigl y Kneale, al proyectar éstos un sistema axiológico objetivo; y en otros.

Lo más necesario es lograr una lógica del valor rigorosa y sin contradicciones, ya que todas las teorías relatadas, sin excepción, carecen de un principio general de estructuración del reino de los valores - cuando reconocen un reino tal. Cuál sea el modo como se deba desenvolver esta lógica del valor constituye todavía un problema, por cierto de dimensiones formidables, puesto que los términos de valor no solamente son "poliguos" - para usar el término de Edwards-, sino que todo término, como lo muestra Ossowska, ${ }^{169}$ puede convertirse bajo ciertas condiciones en un término de valor. Decir que la amapola es roja es enunciar un hecho. Pero decirle a una señora que su nariz es roja es enunciar un valor. Así, pues, independientemente de que definamos el valor por términos característicos o por el impacto emotivo, hallamos en nuestro camino dificultades que deben ser despejadas antes de que intentemos una teoría firme y rigorosa. Bar-Hillel ${ }^{160}$ trata de resolver el dilema de Ossowska dando una fundamentación lógica a la escuela contextual o "de los pronunciamientos". Bar-Hillel propone que en el grupo comprensivo de las frases indicativas se distinga entre las frases indicativas que son independientes del contexto y las que se presentan como dependientes del contexto. BarHillel cree que todas las frases éticas - si es que no todos los juicios de valor- dependen del contexto (del tipo de "todos los actos de engaño son malos"). Tanto la lógica aristotélica como la moderna, dice, han cerrado los ojos a esta distinción. Por otra parte, Kalinowski ${ }^{161}$ trata de mostrar que las 
enunciaciones normativas siguen una lógica análoga a las de las proposiciones modales de Aristóteles. Von Wright ${ }^{162}$ ha desenvuelto una lógica modal detallada, que comprende la "modalidad deóntica"; ${ }^{163}$ y las investigaciones de García Máynez en el campo de la ontología y la lógica formales de las normas jurídicas ${ }^{164.167}$ tienen, según Bobbio, ${ }^{168}$ fundamental importancia para toda disciplina normativa.

Los esfuerzos de Mitchell y Timur, ${ }^{169}{ }^{170}$ por una parte, y los de Christoff, Urmson y Robert S. Hartman, por otra parte, apuntan directamente al propósito de explicar la esencia de los juicios de valor, con amplias posibilidades de aplicación. Los primeros proponen un sistema axiológico brasado en la relación formal de mejoramiento; los segundos ofrecen procedimientos para una lógica del valor, la cual, en diferentes sentidos haga uso de la noción de plenitud del ser lógico, y tenga de este modo una conexión con lo que llamamos axiologia perennis.

Que una relación formal de mejoramiento se halla como subyacente en todos los juicios de valor es un punto que fue ya visto hace mucho tiempo por Brogan, ${ }^{\mathbf{1 7 1}}$ y que además es sugerido por las varias teorías que hacen uso de esta relación, durante el período aquí relatado, como por ejemplo, las de Lamont, Glansdorff, Davidson et al., de las que ya me he ocupado más arriba. Mitchell ${ }^{172}$ desenvuelve las sugerencias de Brogan, hasta convertirlas en un sistema de ética enteramente desarrollado, es decir, en una ética que es sistemática por su estricta trama axiológica. Esta teoría comienza ocupándose con la noción de "mejor", como un término no definido, y define lo "bueno" como "aquello cuya existencia es mejor que su no-existencia". Tomemos A, B, C, ... como símbolos de objetos entre los cuales hay una relación de "mejor que" o "peor que". Estos objetos son "valores". Entonces tenemos como término originario: mejor que, y como definiciones: A es peor $q u e B=B$ es mejor que $A$. Esto define "peor" como lo inverso de la relación "mejor". A es igual (en valor) $a B=A$ no es mejor que $B, y A$ no es peor $q u e B$. Este postulado enuncia la índole transitiva de la relación "mejor que", y es la base del carácter en serie del valor, $y$, por lo tanto, del concepto de una escala de valores. Análogamente a la escala de las cosas buenas hay una escala de las cosas malas, las cuales cada una es peor que las otras precedentes.

El carácter que el valor tiene de darse en serie lleva a Mitchell al problema del bien supremo y a la noción de una clase de valores transfinitos. El hecho de que los valores conocidos empíricamente puedan ser estructurados o dispuestos en una serie ordenada por la relación de "mejor" y "peor" no excluye la posibilidad de que haya valores infinitos, concebibles por la razón, los cuales éstén situados por encima de los valores finitos relacionales, y no pertenezcan a la serie. "El Bien" de Platón y otras formas eternas concebidas por el mismo filósofo serían ejemplos de tales bienes transfinitos. Así como el científico emplea el isomorfismo de su colección de fenómenos valiéndose de 
una colección de construcciones matemáticas para entender. aquellos fenómenos, así Mitchell, de modo análogo, emplea una colección de construcciones matemáticas, la de los números transfinitos, para comprender un conjunto de fenómenos de valor, de "bienes supremos". Dice Mitchell que si la escala de valores no tiene un miembro supremo, hay por lo menos la clase de todos los bienes: y esta clase constituye el Bien como valor transfinito. Al hilo de la misma analogía se puede concebir otros valores transfinitos, p.e., la Verdad y la Belleza, como formando un reino de valores transfinitos, con exacta analogía a la serie de los números naturales que no tienen límite superior pero que, en tanto que una clase, forman un número transfinito.

Christoff ${ }^{173}$ utiliza la idea de plenitud del ser lógico para la "fundamentación de una lógica de los valores", de la siguiente manera muy aguda: Todo juicio de hecho trasciende su contenido y está acompañado por un juicio de valor, puesto que implica la elección del marco de referencia u orden dentro del cual se ha de determinar su verdad o su falsedad. Así, los valores pueden ser definidos como aquello de que carece un concepto, para que el juicio, del cual dicho concepto es el sujeto, pueda ser reconocido como objetivamente verdadero. De esta guisa, el valor de un concepto reside en la incertidumbre o indeterminación del concepto. En tanto que el concepto sea general y constituya una parte de un sistema bien definido de otros conceptos, su valor es casi cero; su valor llega a su punto más alto cuando es un concepto singulär que no pertenece a ningún orden, o cuando constituye un summum genus. Entonces, el valor no es más que la idea positiva de una carencia o menester; significa una cierta nada, una nada no en cuanto al ser, sino en cuanto a la determinación logica.

Mientras que Christoff cambia la plenitud del ser lógico en su opuesto para convertir la carencia o menester de tal ser en la base del valor, Urmson ${ }^{174}$ transforma la universalidad del ser lógico en particularidad - de acuerdo con la escuela de Oxford- $y$, a través de esta reinterpretación da a ese ser lógico una forma que pueda hacerlo adecuado para resolver el dilema de Ossowska. En lugar de hablar de las cualidades que constituyen una cosa, habla de "criterios", con lo cual quiere significar las cualidades de la cosa en tanto que son utilizadas para valorarla -es decir, empleando la terminología de otros autores tratados más arriba, las cualidades "determinantes del valor" de una cosa, utilizadas precisamente en tanto que determinan su valor. A través de este cambio de terminología, Urmson transforma el contexto Ibgico en valorativo: en vez de la propiedad de valor, habla de las "etiquetas estimativas" ("grading labels"); en vez de definiciones de conceptos o de cosas, habla de "definiciones de cualidades" y de "normas de calificación". Según Urmson, "bueno" es una "etiqueta estimativa aplicable en muchos contextos diferentes, pero con criterios diferentes en cuanto a su empleo en cada uno de esos contextos" La relación entre los criterios de bondad y la bondad misma de la 
cosa no es ni analítica ni sintética. No es analítica, puesto que si la etiqueta estimativa "bueno" fuese en cada caso "una mera taquigrafía para la suma de los criterios (naturalismo), entonces nos encontraríamos con la situación ábsurda de que 'bueno' fuera un homónimo con tantos significados equívocos (al modo de juegos de palabras) cuantas fuesen las situaciones a que se aplicara. No podría usarse adecuadamente aplicándolo a una representación teatral en el sentido en que se usa refiriéndolo a una manzana". Urmson cree que esto "constituye una refutación superlativamente gráfica del naturalismo". Según otros escritores, por ejemplo Edwards, esta "poligüidad" precisamente sirve como base para el naturalismo que sostienen. "Por otra parte, el considerar como sintética la relación entre 'bueno' y los criterios para una buena manzana es igualmente absurdo." Si una manzana tiene todas las cualidades de una manzana buena, sería absurdo decir que no fuese una manzana buena. Entonces, dcuál es la relación entre los criterios que hacen buena una cosa y lo "bueno"? Los criterios son diferentes en cada situación, pero la bondad o maldad es determinable objetivamente. No se trata meramente de un asunto de preferencias subjetivas. Es más bien un asunto de la aceptación de los criterios estimativos. Si hay una mayoría estable de gente que prefiere, por ejemplo, el queso que tenga las características A, B, C, entonces estas características son las aceptadas, incluso por la minoría, para calificar el queso, y aquel queso que las posea es "bueno". Se puede determinar de este modo incluso la bondad moral.

Robert S. Hartman, ${ }^{175.182}$ autor del presente artículo, emplea el concepto de la plenitud del ser lógico en su sentido directo. Las propiedades determinantes de lo bueno o que hacen buena una cosa, implican que ésta tiene la propiedad de la bondad. Al desarrollar lógicamente esta premisa, Robert S. Hartman construye una lógica axiológica de los términos, relaciones, proposiciones y valores-de-verdad. Partiendo de la lógica de los valores, surge un cálculo del valor debido a la diferente complejidad o "plenitud"de los conceptos que las cosas pueden cumplir para ser buenas (o que pueden dejar de cumplir para ser malas). Según que los conceptos sean sintéticos (construcciones), analíticos (abstracciones) o singulares, el número de propiedades posibles que ellos pueden contener es, respectivamente, finito, numerablemente infinito, o no-numerablemente infinito. El cumplimiento de estos respectivos conceptos da lugar respectivamente al valor sistémico, al extrínseco, y al intrínseco. De este modo, surge una jerarquía de los valores, que no solamente confirma el isomorfismo de Mitchell de la matemática y la valoración trasfinitas, sino también la escala de valores de Christoff -si bien es contraria a los supuestos de que se sirve éste-, y da una interpretación matemática a la argumentación de Urmson. ${ }^{177}$ Además, por una parte, la definición se basa en un examen del empleo, así como del uso de la palabra "bueno", ${ }^{166} \mathrm{y}$, por otra parte, se basa sobre tres consideraciones deductivas de su significado, 
la primera basada en la axiología de G. E. Moore, ${ }^{179}$ la segunda en el método científico, especialmente del modo como fue practicado por Galileo, ${ }^{180}$ y la tercera en la poliguiidad u homonimia del término "bueno". ${ }^{175-180} \mathrm{La}$ paradoja de Moore de "las dos proposiciones diferentes, ambas verdaderas, de la bondad, a saber: 1) que la bondad depende sólo de la naturaleza intrínseca de lo que la posee... y 2) que, aunque sea así, la bondad, sin embargo, no es una propiedad intrínseca", ${ }_{183}$ se resuelve como todas las paradojas, es decir, mostrando los diferentes planos lógicos: la proposición negativa -que atañe a lo que la bondad no es- - se refiere a la cosa misma; y la proposición positiva -que atañe a lo que la bondad es - se refiere al concepto de la cosa. Pues si "bueno" es una propiedad que indica que se cumple la dimensión intensiva o comprensiva del concepto de la cosa, entonces la bondad no es una propiedad de la cosa misma, sino que es una propiedad del concepto de la cosa, a saber, que la dimensión intensiva o comprensiva de ese concepto se cumple por la cosa. La segunda deducción compara el enfoque que Galileo dio al problema del movimiento con un posible enfoque axiológico del problema del valor. En ambos casos el problema consiste en encontrar una regla de medida. Galileo encontró la regla de medida del movimiento en el prescindir de las cualidades secundarias del fenómeno y en el concentrar su atención en sus cualidades primarias, es decir, en las cualidades que pueden ser sometidas a medida -centímetros, gramos, segundos-; de suerte que lo que se medía no era el fenómeno sensorial de la vida ordinaria dotado de sus cualidades secundarias, sino una construcción que constaba de propiedades primarias. En la medición del valor, lo que se ha de medir es el objeto sensible ordinario, no sólo en tanto que posee sus propiedades secundarias, sino que además precisamente esta posesión es lo que mide o determina su valor. Por lo tanto, para la medición del valor, se debe emplear las propiedades secundarias como propiedades primarias. La cuestión consiste en encontrar la pauta o regla que sea respecto de las propiedades secundarias lo que las pautas o reglas primarias - de longitud, peso, etc.-, son respecto de las propiedades primarias. $\mathrm{O}$, expresado en otras palabras: ¿Qué es lo que contiene las propiedades secundarias del modo como, por así decirlo, el metro contiene el centímetro? La respuesta es la siguiente: la dimensión intensiva o comprensión de un concepto. El concepto sirve como la pauta o regla para la medición del valor - el mismo resultado al que lleva la deducción partiendo de Moore. La tercera deducción conduce al mismo resultado, y demuestra, además, el carácter puramente formal y no-naturalista de la teoría en cuestión. Como los autores que se han ocupado de axiología, desde Arištóteles a Edwards lo han apuntado, aunque otros escritores como Urmson lo hayan negado, "bueno" es un homónimo aplicable en muchos contextos diferentes con una diferente colección de criterios para su empleo en cada contexto. Esto constituye una descripción exacta de la índole lógica de la variable. "Bueno" es una variable, y 
sus valores son comprensiones efectivamente cumplidas. "Bueno" es esta variable cuyos valores lógicos son valores axiológicos. Su índole variable se expresa en leyes de valor, al igual que, por ejemplo, la índole variable de la gravitación se expresa en leyes de la naturaleza. La variable "bueno" tiene una extensión o un alcance infinito —que en la axiología escolástica la convirtió en uno de los trascendentales-, y este alcance está estructurado, pues un concepto puede tener cualquiera de las tres complejidades comprensivas, la constructiva, la abstractiva y la singular, de suerte que su cumplimiento puede ser ora un valor sistémico, ora un valor extrínseco, u ora un valor intrínseco. La lógica de las complejidades comprensivas y de las reglas de aplicación da estructura a los conceptos de von Rintelen de Valor-real (Real-Wert) y Valorideal (Wert-Idee), y suplementa la explicación macroscópica de Northrop de la correlación epistémica con una explicación microscópica de ella. Al mismo tiempo, esta teoría de R. S. Hartman sigue el programa de Margenau, de usar el método de la ciencia, bien que no el contenido de ésta. Por tal razón, esta teoría es formal de tipo no-naturalista: aplica el método científico a un tema sui generis, a saber, al valor. Las aplicaciones de esta teoría, así como de otras doctrinas plenamente cognoscitivistas, a la realidad de los valores muestran la fecundidad de las técnicas axiológicas exactas para la inteligencia del sentido de la vida — un ideal hacia cuya realización la teoría de los valores va progresando inexorablemente.

Robert S. Hartiman

\section{BIBLIOGRAFIA}

(Los números que figuran antes de cada título corresponden a las llamadas en el texto, e indican, por lo tanto, el lugar de éste en donde se alude a su contenido.)

Abbagnano, N., (95) Possibilitd e libertd, Turin, 1956.

Alcorta, J. I., (118) Destino humano y ethos, Revista de Filosofía, 12, 31-58 (1953).

Allers, R., (36) The Failure of Communication in Ethics (Discussion), Symbols and Values: an Initial Study, Bryson, L. et al., ed., New York, 1954.

Aristotle, (10) Nicomachean Ethics, Bk.I, Ch.6.

Austin, J. L., (13) Other Minds, Proc. Arist. Soc. Suppl., 20, 148-187 (1946).

Ayer, A. J., (2) Language, Truth and Logic, London, 1936. 2nd ed., London, 1946.

Bagolini, L., (96) La simpatia nella morale e nel diritto, Bologna, 1952.

- (97) Valutazioni morali e giuridiche nella crisi dell' etica individuale, Siena, 1950. (98) Value Judgments in Ethics and in Law, Philosophical Quarterly, 1, 423-432. (1951).

Bahdur, Sri J. C. W., (139) An Aspect of Indian Aesthetics, Mysore, 1956.

Banfi, A., (79) L'uomo copernicano, Milan, 195.

Bar-Hillel, Y., (160) On the Character of the Ethical Judgment, Iyyun, 5, 18-24.

Barnes, W.H.F., (4) Ethics Without Propositions, Proc. Arist. Soc. Suppl., 22, 1-30 (.1948).

Battaglia, F., (99) Filosofia del lavoro, Bologna, 1951.

- (100) Arte e moralitd, Bologna, 1952. 
- (101) Il concetto spiritualistico della storia, Bologna, 1953.

- (102) Morale e storia nella prospettiva spiritualistica, Bologna, 1953.

Baylis, C. A., (72) The Confirmation of Value Judgments, Philosophical Review, 51, 50-58 (1952).

Bobbio, N., (168) La Logica giuridica di Eduardo García Máynez, Rivista Internazionale di Filosofia del Diritto, 31, 644-669 (1954). También La Lógica jurídica de Eduardo García Máynez, Universidad Nacional de México, 1956.

Braithwaite, R. B., (62) Scientific Explanation, A Study of the Function of Theory, Probability and Law in Science, Cambridge, 1953.

- (63) Theory of Games as a Tool for the Moral Philosopher, Cambridge, 1955.

Brogan, A. P., (171) The Fundamental Value Universal, Journal of Philosophy, 16, 96-104 (1919).

Buber, M., (92) Urdistanz und Beziehung, Heidelberg, 1951.

- (93) Dialogisches Leben, Zürich, 1947.

Campbell, C. A., (6) Ethics Without Propositions, Mind, 59, 88-93 (1950).

Capograssi, G., (109) Introduzione alla vita etica, Turin, 1950.

Carlberg, G., (44) Om människans behov och värden ("Sobre las necesidades y los valores del hombre") Stockholm, 1950.

Christoff, D., (154) La tâche d'une morale philosophique, Revuc de Théologie et de Philosophie, II, 107-119 (1952).

- (155) Contemplation et Création, Revue de Théologie et de Philosophie, II, 108122 (1953).

- (173) Le fondement logique des valeurs, Proc. $\mathrm{X}$ Int. Cong. Phil., pp. 454-455, Amsterdam, 1949.

Corkey, R., (142) Basic Intrinsic Ethical Values, Philosophy, 29, 321-331 (1954).

Croce, B., (89) Indagini sullo Hegel e Schiarimenti filosofici, Bari, 1952.

Cross, R. C., (16) The Emotive Theory of Ethics, Proc. Arist. Soc. Suppl., 22, 127-140 (1948).

Davidson, D., McKinsey, J. C. C., Suppes, P., (61) Outlines of a Formal Theory of Value, I, Stanford, Cal., 1954.

Edel, A., (21) Ethical Reasoning, Academic Freedom, Logic, and Religion, White, M., ed., Philadelphia, 1953.

(42) Ethical Judgment, Glencoe, Ill., 1955.

Edwards, P., (9) The Logic of Moral Discourse, Glencoe, Ill., 1955.

Ewing, A. C., (70) A Middle Way in Ethics? Analysis, 13, 33-38 (1952). (71) Ethics, London, 1953.

Falk, W. D., (19) Goading and Guiding, Mind, 62, 145-171 (1953).

Farré, L., (115) Fundamentos para una metafísica de los valores en Aristóteles, Act. Cong. Int. Phil., Barcelona, 1948, II, 735-754.

Feigl, H., (30) De Principiis Non Disputandum. . . P Philosophical Analysis, Black, M., ed., Ithaca, N. Y., 1950.

- (31) Validation and Vindication, An Analysis of the Nature and the Limits of Ethical Arguments, Readings in Ethical Theory, Sellars, W., and Hospers, J., ed., New York, 1952.

Ferrater Mora, J., (40) Wittgenstein, A Symbol of Troubled Times, Philosophy and Phenomenological Research, 14, 89-96 (1953).

Frondizi, R. ( 128 bis), Sobre la Objetividad de los Valores, IV Congreso Interamericano de Filosofía, Santiago de Chile, 1956.

_ Valor y situación, V Congreso Interamericano de Filosofía, Washington, 1957.

García Máynez, E., (149) La Definición del Derecho, México, 1948. (150) The Philosophical-Juridical Problem of the Validity of Law, Latin-American Legal Philosophy, Cambridge, Mass., 1948.

- (151) Das Problem der Definition des Rechts, Österr. Zeitschr. f. öfftl. Recht, 3, 307-330 (1951).

- (164) Introducción a la Lógica Juridica, México, 1951. 
(165) Los Principios de la Ontología Formal del Derecho y su expresión simbólica, México, 1953.

(166) La Lógica déntica de G. H. Von Wright y la Ontología Formal del Derecho Revista de la Facultad de Derecho de México, III, 9, pp. 10-37 (1953).

(167) Lógica del Juicio Jurídico, México, 1955.

Gauss, H., (158) Allgemeine Einleitung in die Platonische Philosophie, Bern, 1952.

Geiger, G., (83) The Problem of Values and the Social Scientist, Journal of Social Issues, $6,1-79(1950)$.

Gentile, G., (90) Genesi e struttura della societd, Florence, 1951.

Gilman, E., (34) Objectivity in Conduct, Philosophy, 29, 308-320 (1954).

Glansdorff, M., (43) Théorie générale de la valeur, Bruxelles, 1954.

Gutwenger, E., (137) Wertphilosophie, Innsbruck, 1952.

Hägerström, A., (8) Inquiries Into the Nature of Law and Morals, Broad, C. D., transl., Uppsala, 1953.

Hall, E. W., (6) What Is ValueP An Essay in Philosophical Analysis, London, 1952. (20) Practical Reason( $s$ ) and the Deadlock in Ethics, Mind, 64, 319-332 (1955).

Hallden, S., (7) Emotive Propositions, Uppsala, 1954.

Hampshire, S., (29) Fallacies in Moral Philosophy, Mind, 58, 466-482 (1949).

Hare, R. M., (26) The Language of Morals, Oxford, 1952.

Harrison, J., (3) Can Ethics Do Without Propositions?, Mind, 59, 358-371 (1950).

Hart, H. L. A., (14) The Ascription of Responsibility and Rights, Proc. Arist. Soc., 49, 171-194 (1948-1949). También en Logic and Language, Flew, A. G. N., ed., Oxford, 1951.

Hartman, R. S., (175) A Logical Definition of Value, Journal of Philosophy, 68, 413-420 (1951).

- (176) Research in the Logic of Value, The Graduate School Record, Ohio State University, 5, 6-8 (1952).

- (177) Group Membership and Class Membership, Philosophy and Phenomenological Research, 13, 353-370 (1953).

- (178) The Analytic and the Synthetic as Categories of Inquiry, Perspectives in Philosophy, Columbus, O., 1953.

- (179) The Analytic, the Synthetic, and the Good: Kant and the Paradoxes of G. E. Moore, Kant-Studien, 45, 67-82 (1953-1954), 46, 3-18 (1954-1955).

- (180) La creación de una Etica científica, Diánoia, Anuario de Filosofía, 1, 205235 (1955).

- (181) Niveles del Lenguaje Valorativo, Diánoia, Anuario de Filosofía, 2, 254-269 (1956).

(182) Véase Lepley (85).

Hartmann, N., (147) Teleologisches Denken, Berlin, 1951.

- (148) Kleinere Schriften, I, Berlin, 1955.

Heidegger, M., (129) Über den Humanismus, Frankfurt, 1949. (130) Holzwege, Frankfurt, 1950.

Hill, T., (141) Contemporary Ethical Theories, New York, 1950.

Hilliard, A. L., (50) The Forms of Value: The Extension of a Hedonistic Axiology, New York, 1950.

Hiriyanna, M., (138) The Quest after Perfection, Mysore, 1952.

Hürlimann, K., (146) Person und Werte, Divus Thomas, 1952, 273-298, 385-416.

Kalinowski, J., (161) Théorie des propositions normatives, Studia Logica, I, Poznan, 1953.

Kecskemeti, P., (37) Meaning, Communication and Value, Chicago, 1952.

Kneale, W., (33) Objectivity and Morals, Philosophy, 25 (1950). Also, Readings in Ethical Theory, Sellars, W. and Hospers, J., ed., New York, 1952.

Kraft, V., (51) Grundlagen einer wissenschaftlichen Wertlehre, Vienna, 1951.

Krings, H., (135) Fragen und Aufgaben der Ontologie, Tübingen, 1954.

Lacroix, J., (80) Marxisme, Existentialisme, Personnalisme, Paris, 1951.

Lamont, W. D., (77) The Value Judgement, Edinburg, 1955. (78) The Principles of Moral Judgement, Oxford, 1946. 
Lanz, H., (32) In Quest of Morals, Stanford University, 1941.

Lavelle, L., (87) Traité des Valeurs, Paris, 1951, 1955.

Lazzarini, R., (94) Intenzionalitd e istanza metafisica, Milan, 1954.

Leclercq, J., (86) Les grandes lignes de la philosophie morale, Louvain, 1954.

(86a) La philosophie morale de Saint Thomas devant la pensée contemporaine, Louvain, 1955.

Lepley, R., ed., (84) Value: A Cooperative Inquiry, New York, 1949.

ed., (85) The Language of Value, New York, 1957.

Le Senne, R., (88) La destinée personnelle, Paris, 1951.

Lewis, C. I., (69) The Ground and Nature of the Right, New York, 1955.

Linares Herrera, A., (119) Elementos para una crítica de la Filosofía de los valores, Madrid, 1949.

Locke, J., (1) Some Thoughts Concerning Education, London, 1695.

Mabbott, J. D., (76) True and False in Morality, Proc. Arist. Soc., 49, 133-150 (19481949).

MacdonaId, M., (15) Ethics and the Ceremonial Use of Language, Philosophical Analysis, Black, M., ed., Ithaca, New York, 1950.

Mackie, J., (25) "The Place of Reason in Ethics", by E. S. Toulmin, Australasian Journal of Psychology and Philosophy, 29, 2 (1950).

Mandelbaum, M., (49) The Phenomenology of Moral Experience, Glencoe, Ill., 1955.

Margenau, H., (64) Scientific Ethics, Scientific Monthly, 69, 290-296 (1949).

- (65) Remarks on Ethical Science, The Nature of Concepts, Their Inter-relations and Role in Social Structure, Stillwater, Okla., 1950.

Marías, J., (121) Introducción a la Filosofía, Madrid, 1956. También Reason and Life, New Haven, 1958.

Maslow, A., (45) Motivation and Personality, New York, 1954.

Mayer, E., (145) Die Objektivität der Werterkenntnis bei Nicolai Hartmann, Meisenheim, 1952.

Mc Cracken, D., (67) Thinking and Valuing, London, 1950.

Mitchell, E. T., (172) A System of Ethics, New York, 1950.

Montero Moliner, F., (118) La teoria de la significación en Husserl y Heidegger, Revista de Filosofía, 12, 393-426 (1953).

Moore, G. E., (183) Philosophical Studies, London, 1948, p. 273.

Muñoz Pérez, J., (116) Aprehensión de los valores, Act. Cong. Int. Phil., I, 439-453, Barcelona, 1948.

Negley, G., (35) The Failure of Communication in Ethics, Symbols and Values: An Initial Study, Bryson, L. et al., ed., New York, 1954.

Nicol, E., (128) Historicismo y existencialismo, México, 1950.

Northrop, F. S. C., (52) The Meeting of East and West, New York, 1946.

- (53) Logic of the Sciences and the Humanities, New York, 1957.

- (54) Naturalist and Cultural Foundations for a More Effective International Law, The Yale Law Journal, 59, 1430-1450 (1950).

(55) The Nature of Concepts and Conceptual Structure, The Nature of Concepts, Their Inter-relations and Role in Social Structure, Stillwater, Okla., 1950.

- (56) The Philosophy of Natural Science and Comparative Law, Proceedings, American Philosophical Association, New York, 1952.

- (57) Criterion of Universal Ethical and Legal Norms, Moral Principles in Action, Anshen, R. N., ed., New York, 1952.

- (58) Ethical Relativism in the Light of Recent Legal Science, Journal of Philosophy, 52, 649-662 (1955).'

- (59) Man's Relation to the Earth in Its Bearing on His Aesthetic, Ethical, and Legal Values, Man's Role in Changing the Face of the Earth, Thomas, W. L., ed., Chicago, 1956.

Nowell-Smith, D. H., (27) Ethics, London, 1954.

Oromi, M., (114) Principios básicos de la ética de Escoto, Verdad y Vida, 13, 393-434 (1955). 
Ossowska, M., (47) Motywy postepowania. Z zagadnien psychologii moralnosci ("La motivación humana. Investigación sobre la psicología de la vida moral”), Warszawa, 1949.

- (159) Qu'est ce qu'un jugement de valeur? Proc. X Int. Cong. Phil., Amsterdam, 1949 , pp. 443-444.

Paton, H. J., (75) The Emotive Theory of Ethics, Proc. Arist. Soc. Suppl., 22, 107-128 (1948).

Pavicevic, V., (144) The Relationship Between Value and Reality in Modern Idealistic Axiology, Belgrade, 1956.

Prior, A. N., (38) Logic and the Basis of Ethics, Oxford, 1949.

Ranga Swami, K. V., (140) Some Aspects of the Hindu Way of Life According to Dharmashästra, Baroda, 1952.

Raphael, D. D., (66) Moral Judgement, London, 1955.

Rapoport, A., (60) Operational Philosophy, New York, 1953.

Recaséns Siches, L., (124) Vida Humana, Sociedad y Derecho, $3^{\mathrm{a}}$ ed., México, 1952. También Human Life, Society, and Law, Latin-American Legal Philosophy, Cambridge, Mass., 1948.

- (123) Nuevo existencialismo en México. La filosofía de José Romano Muñoz, Cuadernos Americanos, 15, 75-89 (1956).

Reding, M., (152) Metaphysik der sittlichen Werte, Düsseldorf, 1949.

Rice, P. B., (28) On the Knowledge of Good and Evil, New York, 1955.

Rickman, H. P., (39) Linguistic Analysis and Moral Statements, Philosophy, 29, 122-130 (1954).

Rintelen, F.-J., von, (134) Der Wertgedanke in der europäischen Geistesentwicklung, Halle, 1932.

(131) Von Dionysus zu Apollon. Der Aufstieg im Ges ite, Wiesbaden, 1948.

- (132) Philosophie der Endlichkeit als Spiegel der Gegenwart, Meisenheim, 1951. (133) Der Rang des Geistes. Goethes Weltverständnis, Tübingen, 1955.

Romano Muñoz, J., (122) Hacia una filosofía existencial, México, 1953.

Russell, B., (48) Human Society in Ethics and Politics, New York, 1955.

Rusell, L. J., (17) Moral Statements as Proposals, Australasian Journal of Psychology and Philosophy, 30, 1 (1952).

Ryle, G., (18) Ordinary Language, Philosophical Review, 62, 167-186 (1953).

Scheler, M., (143) Der Formalismus in der Ethik und die materiale Wertethik, Bern, 1954.

Sciacca, M. F., (103) Il pensiero moderno, Brescia, 1949.

- (104) Filosofia e metafisica, Brescia, 1950.

- (105) L'interiorité objective, Milan, 1952.

- (106) In spirito $e$ veritd, Brescia, 1952.

- (107) L'ora di Cristo, Milan, 1952.

- (108) La filosofia per la vita, Brescia, 1952.

Siewerth, G., (136) Thomas von Aquinas. Die menschliche Willensfreiheit, Düsseldorf, 1954.

Spirito, U., (91) Vita come amore, Florence, 1953.

Stofer, H., (68) Uber das ethische Werturteil, Basel, 1955.

Straus, L., (82) Social Science and Humanism, Iyyun, 7, 65-73.

Timur, M., (169) Better as the Value-Fundamental, Mind, 64, 52-60 (1955).

- (170) The Theory of Morals, London, 1956.

Toulmin, S. E., (23) Knowledge of Right and Wrong, Proc. Arist. Soc., 50, 139 ff., (19491950).

(24) An Examination of the Place of Reason in Ethics, Cambridge, 1950.

(22) Is There a Fundamental Problem in Ethics? Australasian Journal of Psychology and Philosophy, 33, 1 (1955).

Urdánoz, T., (113) Filosofía de los valores y filosofía del ser, Ciencia Tomista, 76, 86-112 (1949).

Urmson, O., (174) On Grading, Mind, 59, 145-169 (1950). También en Logic and Language, II, Flew, A. G. N., ed., Oxford, 1953. 
- (74) Some Questions Concerning Validity, Revue Internationale de Philosophie, $25,217-229$ (1953).

Vivas, E., (153) The Moral Life and the Ethical Life, Chicago, 1950.

Von Wrigth, G. H., (162) Modal Logic, Amsterdam, 1951. (163) Deontic Logic, Mind, 60, 1-15 (1951).

Werkmeister, W. H., (125) On Describing a World, Philosophy and Phenomenological Research, 11, 303-325 (1951).

- (126) Problem of Value Theory, Philosophy and Phenomenological Research, 12, 495-512 (1952).

- (127) Prolegomena to Value Theory, Philosophy and Phenomenological Research, 14, 293-308 (1954).

Whitehead, A. N., (41) Science and the Modern World, Cambridge, 1933, p. 41.

Wick, W. A., (73) Moral Problems, Moral Philosophy, and Metaethics: Some Further Dogmas of Empiricism, Philosophical Review, 52, 3-22 (1952).

Widmer, G., (156) Les valeurs et leur signification, Neuchâtel, 1950.

(157) La conscience des valeurs, Studia Philosophica, 1953, 135-156.

Wittgenstein, L., (12) Tractatus Logico-Philosophicus, London, 1922, p. 77. (11) Philosophical Investigations, Oxford, 1953.

Wolff, W., (46) Values and Personality, New York, 1950.

Zaraguieta, J., (110) Ser y valer, Act. Cong. Int. Phil., Barcelona, 1948, II, 563-597.

(111) La double perspective de la philosophie comme connaissance de l'être et comme estimation de la valeur, Proc. X Cong. Int. Phil., Amsterdam, 1949, 345-346. (112) Fílosofia y vida, Madrid, 1950-1954 (3 vols.).

Znaniecki, F., (81) Cultural Sciences. Their Origin and Development, Urbana, Ill., 1952. 